The Free Internet Journal

for Organic Chemistry
Review

Arkivoc 2018, part ii, 170-191

Archive for

Organic Chemistry

\title{
Recent contributions to the Diversity-Oriented Synthesis (DOS) mediated by iminium ions through multicomponent Mannich-type reactions
}

\author{
Rodrigo Abonia, $*^{a}$ and Juan C. Castillo ${ }^{a, b}$ \\ ${ }^{a}$ Department of Chemistry, Universidad del Valle, A. A. 25360, Cali, Colombia \\ ${ }^{b}$ Grupo de Investigación Núcleo, Departamento de Química y Bioquímica, Universidad de Boyacá, Carrera 2 a \\ Este No. 64-169, Tunja, Colombia \\ E-mail: rodrigo.abonia@correounivalle.edu.co
}

Dedicated to Prof. Kenneth K. Laali in his 65th birthday and for his research and scholarly achievements in different topics of the organic chemistry spanned over 35 years

Received 07-30-2017

Accepted 09-22-2017

Published on line 11-29-2017

\section{Abstract}

This short account summarizes the most recent contributions of the author and his collaborators to the Diversity Oriented Synthesis (DOS) mediated, at least in a step of the process, by Mannich-type reactions (MTR) and using formaldehyde as common starting material in all cases. Through this strategy, diverse nitrogen-containing acyclic and heterocyclic systems were synthesized, whether in straightforward or multicomponent approaches.

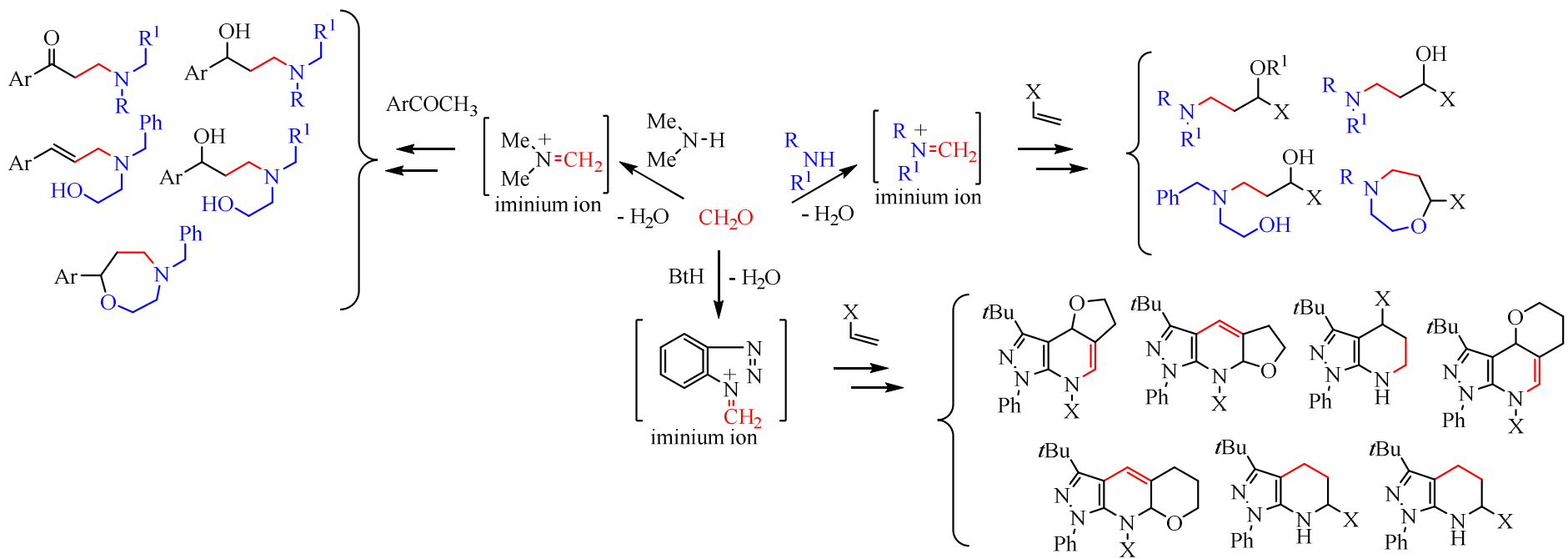

Keywords: Formaldehyde, multicomponent reactions, Mannich-type reactions, Diversity Oriented Synthesis, nitrogen-containing derivatives, combinatorial synthesis 


\section{Table of Contents}

1. Introduction

2. Synthesis of Novel Hydropyrazolopyridine Derivatives under Solvent-Free Conditions via Benzotriazole Methodology

3. An Efficient Catalyst-Free Four-Component Synthesis of Novel $\gamma$-Aminoethers Mediated by a Mannich-Type Reaction

4. A Facile Synthesis of Stable $\beta$-Amino- $N$-/O-Hemiacetals Through a Catalyst-Free Three-Component Mannich-Type Reaction

5. A Straightforward and Efficient Method for the Synthesis of Diversely Substituted $\beta$-Aminoketones and $\gamma$ Aminoalcohols from 3-(N,N-Dimethylamino)propiophenones as Starting Materials through a Mannich-Type Strategy

6. A Straightforward Synthesis of 4,7-Disubstituted 1,4-Oxazepanes via a Brønsted Acid-Catalyzed Intramolecular Etherification Reaction

7. Summary

Acknowledgements

References

\section{Introduction}

It is well-known that multicomponent reactions (MCRs) are convergent reactions, in which three or more starting materials react in a single chemical step to form a product that incorporate substantial portions of all components, ${ }^{1}$ (e.g. Mannich, ${ }^{2}$ Strecker, ${ }^{3}$ Hantzsch, ${ }^{4}$ Ugi, ${ }^{5}$ Biginelli, ${ }^{6}$ Passerini, ${ }^{7}$ Willgerodt-Kindler, ${ }^{8}$ etc., among other reactions). In a MCR, a product is assembled according to a cascade of elementary chemical reactions. Thus, there is a network of reaction equilibria, which all finally flow into an irreversible step yielding the product. Applications of MCRs in all areas of applied chemistry are very popular because they offer a wealth of products, while requiring only a minimum of effort. As opposed to the classical way to synthesize complex molecules by sequential synthesis, MCRs allow the assembly of complex molecules in a one-pot manner. Unlike the usual stepwise formation of individual bonds in the target molecule, the defining attribute of MCRs is the inherent formation of several bonds in one operation without isolating the intermediates (referred to as the bond-forming efficiency, BFE), ${ }^{9-11}$ changing the reaction conditions, or adding further reagents.

The Mannich reaction is a classical reaction, belonging to the multicomponent reactions (MCR's) family, ${ }^{12}$ which typically have been used for the synthesis of $\beta$-aminocarbonyl compounds (i.e. Mannich bases) $\mathbf{5}$. These latter compounds are key intermediates in the synthesis of different pharmaceutical and natural occurring products as well as Michael acceptor precursors. ${ }^{13}$ The typical Mannich reaction involves the reaction between enolizable aldehydes or ketones 1, formaldehyde $\mathbf{2}$ and primary/secondary amine hydrochlorides $\mathbf{3}$ in a protic solvent, as shown in Scheme 1, the iminium ion 4 being the key species in this process. 


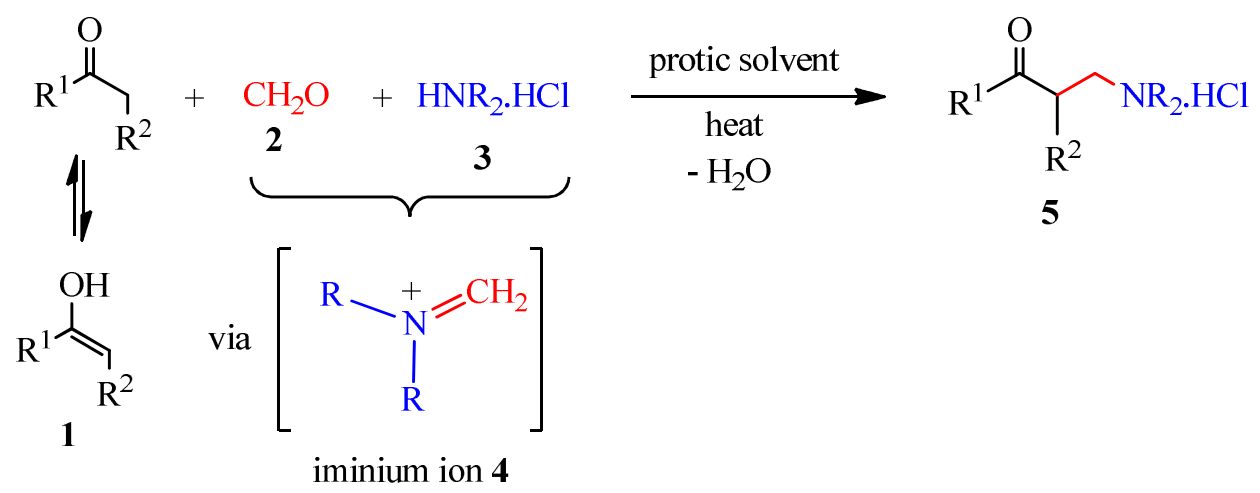

Scheme 1. Classical approach for the Mannich reaction.

Modern variants of Mannich reaction (called Mannich-type reactions-MTR), are carried out in simplest ways and short reaction times through pre-formed electrophiles such as iminium salts, imines or benzotriazolyl aminals, as well as diverse nucleophiles instead of enolizable aldehydes and ketones like enolates, vinyl ethers or enamines.

On the other hand, Diversity-Oriented Synthesis (DOS), describes the synthesis of structurally diverse collections of small molecules from simple starting materials, typically through the use of "split-pool" combinatorial chemistry. ${ }^{14-15}$ This approach is analyzed in the direction of chemical reactions, i.e. from reactants to products, using forward synthetic analysis, Figure $1 .{ }^{16}$ Although complexity and diversity can be analyzed separately, the design of the synthetic pathway should integrate both features as a final step in the analysis.

\section{Diversity-oriented synthesis}

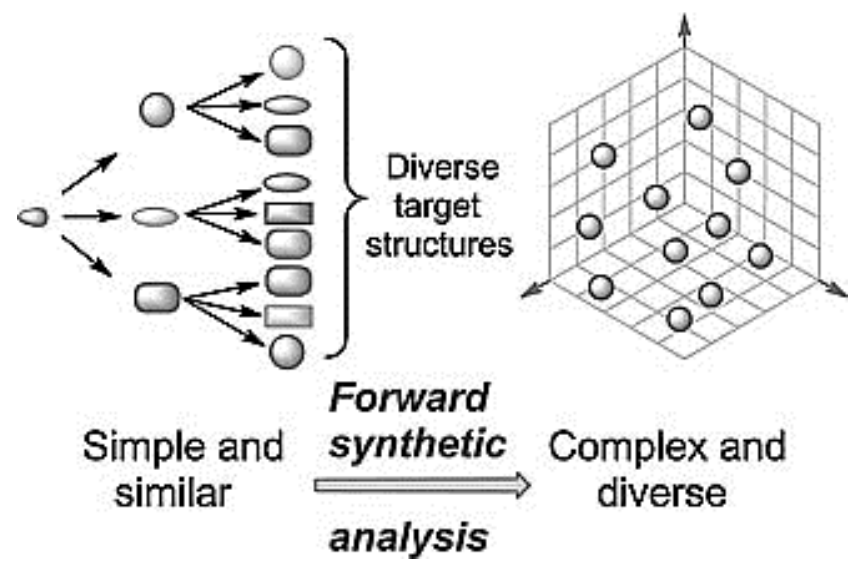

Figure 1. Schematic sequence for a DOS strategy. ${ }^{6}$

In this sense, the goals of DOS include the development of pathways leading to the efficient (three- to fivestep) synthesis of collections of small molecules having skeletal and stereochemical diversity with defined coordinates in the chemical space. Although the DOS do not permit the application of retrosynthetic concepts and thinking (like Target-Oriented Synthesis (TOS) or Combinatorial Chemistry), these foundations are being built on, by using parallel logic, to develop the complementary procedure known as forward-synthetic analysis, which facilitates the synthetic planning, communication, and teaching in this evolving discipline of the organic chemistry. 
In consequence, we initially evaluated the reactivity of benzotriazolyl derivatives of pyrazoles (acting as pre-formed electrophiles) with activated alkenes (acting instead of enolizable aldehyde or ketone) as it is presented below:

\section{Synthesis of Novel Hydropyrazolopyridine Derivatives under Solvent-Free Conditions via the Benzotriazole Methodology}

Pyrazolopyridines and their hydroderivatives are compounds of our interest owing to the biological activities displayed for many of them. ${ }^{17-19}$ Using some previous results as starting point, ${ }^{20-22}$ we successfully synthesized novel triaza-indacene and triaza-cyclopentanaphthalene derivatives $11,14\{3\}$ and $11,14\{4\}$ respectively, and tetrahydropyrazolopyridines $12\{1\}, 13\{2\}$ and $15\{1\}$ in acceptable to good yields, from the reaction of benzotriazolylmethylaminopyrazoles 8 and $\mathbf{9}$ with the representative terminal alkenes 10\{1-4\}, following the benzotriazole methodology in solvent-free conditions, under the presence of $p$-toluenesulfonic acid (PTSA) as catalyst. $^{23}$

In our protocol, pyrazolo-benzotriazolyl derivatives 8 and $\mathbf{9}^{24-25}$ were initially prepared as depicted in Scheme 2. The starting hydroxymethylbenzotriazole $\mathbf{7}$ was previously obtained by reacting benzotriazole (BtH) and formaldehyde $\mathbf{2}$ in a hot aqueous solution.

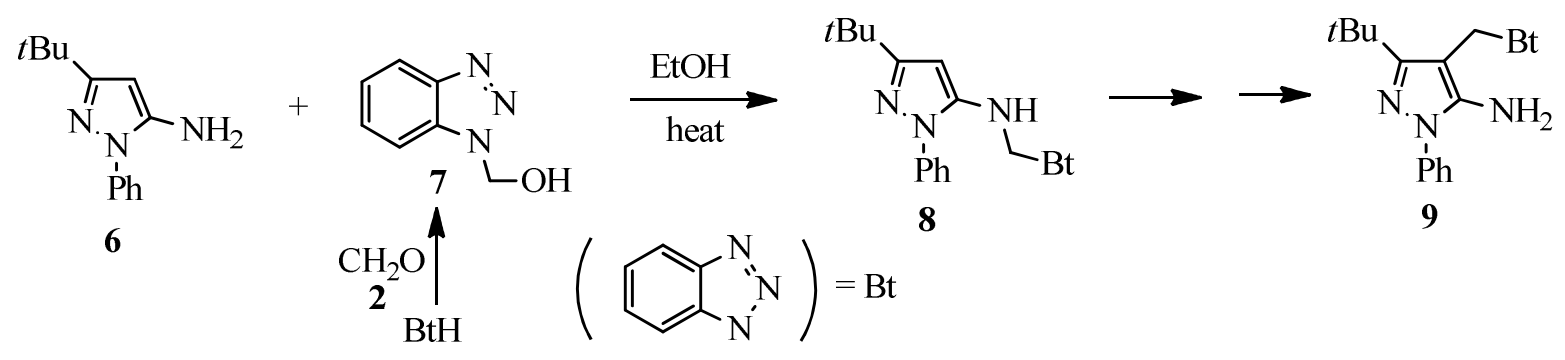

Scheme 2. Synthesis of the pyrazolo-benzotriazolyl derivatives 8 and $9 .^{23}$

The next step consisted in reaction of a chemset of activated alkenes 10\{3-4\}, Figure 2, with the benzotriazolyl derivatives 8 and 9 in a (1:5 ratio of 8/9:10, respectively), in the presence of PTSA.

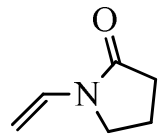

$10\{1\}$

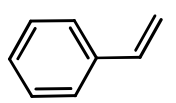

$10\{2\}$

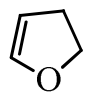

$10\{3\}$

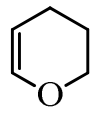

$10\{4\}$

Figure 2. Activated terminal alkenes $\mathbf{1 0}$ employed for reacting with the starting compounds $\mathbf{8}$ and $\mathbf{9} .^{23}$

In the case of the starting compound $\mathbf{8}$, the novel angular triaza-as-indacene $\mathbf{1 1}\{3\}$ and triazacyclopenta[a]naphthalene $\mathbf{1 1}\{4\}$ were obtained as oily materials in $70 \%$ and $75 \%$ yields when the cyclic alkenes $\mathbf{1 0}\{3\}$ and $\mathbf{1 0}\{4\}$ were used, respectively. Meanwhile, the bicyclic products $\mathbf{1 2}\{1\}$ and $\mathbf{1 3}\{2\}$ were obtained in $66 \%$ and $80 \%$ yield, when alkenes $10\{1\}$ and $10\{2\}$ were used, respectively, Scheme 3. 


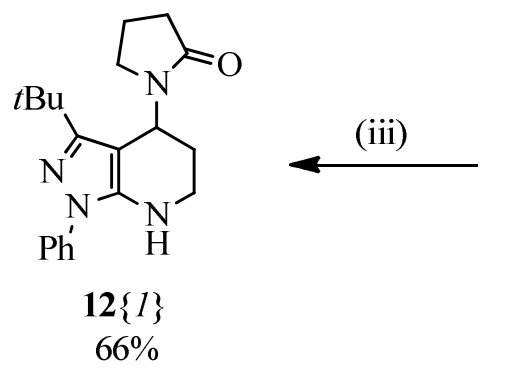

(i) or (ii)

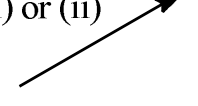

8

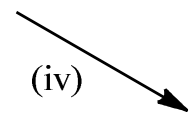

$t \mathrm{Bu}$<smiles>BrCc1n[nH]c2c1C1OCCC1=CN2</smiles>

$\mathrm{Ph}^{\prime}$<smiles>[AlH]C1CCCO1</smiles>

$11\{3\}$

$70 \%$

$t \mathrm{Bu}$

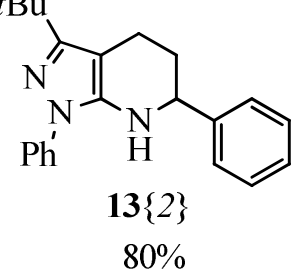

or<smiles>CC(C)Cc1n[nH]c2c1C1OCCCC1=CN2</smiles>

Ph'<smiles>CC1CCCCO1</smiles>

$11\{4\}$

$75 \%$

Conditions: (i) = 2,3-dihydrofuran (5 eq.) 10\{3\}, PTSA, heat; (ii) = 3,4-dihydro-2H-pyran (5 eq.) 10\{4\}, PTSA, heat; (iii) = N-vinyl-2pyrrolidinone (5 eq.) 10\{1\}, PTSA, heat; (iv) = styrene (5 eq.) 10\{2\}, PTSA, heat.

Scheme 3. Reaction products from pyrazole derivative 8 via benzotriazole methodology under solvent-free conditions. $^{23}$

Application of the above approach to the starting compound 9 led to the corresponding linear triaza-sindacene $14\{3\}$ and triaza-cyclopenta[b]naphthalene $14\{4\}$ in $62 \%$ and $68 \%$ yield, respectively, as well as the tetrahydropyrazolopyridines $13\{2\}$ and $15\{1\}$ as oily materials in $80 \%$ and $50 \%$ yield, respectively, Scheme 4 .

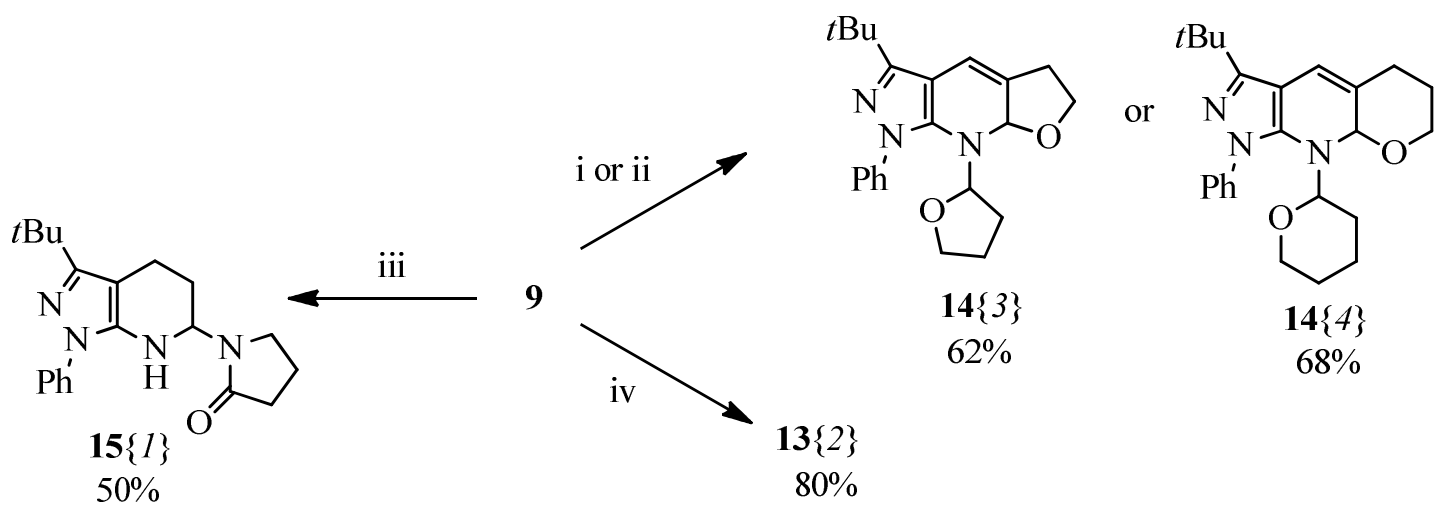

Scheme 4. Reaction products from pyrazole 9 via benzotriazole methodology under solvent-free conditions. ${ }^{23}$

It is assumed that compounds 11 and 14 (1:2-adducts), resulted from a heterocyclization reaction of compounds 8 and 9 with one equivalent of cyclic alkenes $10\{3\}$ and $10\{4\}$, respectively. A subsequent $N$ alkylation reaction of the intermediate type $18\{3\}$ with a second molecule of the same alkenes 10 on the free $\mathrm{N}-\mathrm{H}$ functionality led the isolated products 11 and 14, Scheme 5. In this process, the starting compound 8 acted as the masked iminium ion type $\mathbf{4}$, the $\mathrm{Bt}$ as a synthetic auxiliary ${ }^{26-27}$ and the olefins $\mathbf{1 0}$ as the nucleophiles to complete the required conditions for a Mannich-type reaction. Formation of benzotriazolyl byproducts type 16 was detected in all cases which characterizes the well-known benzotriazole methodology. ${ }^{26-}$ 27 

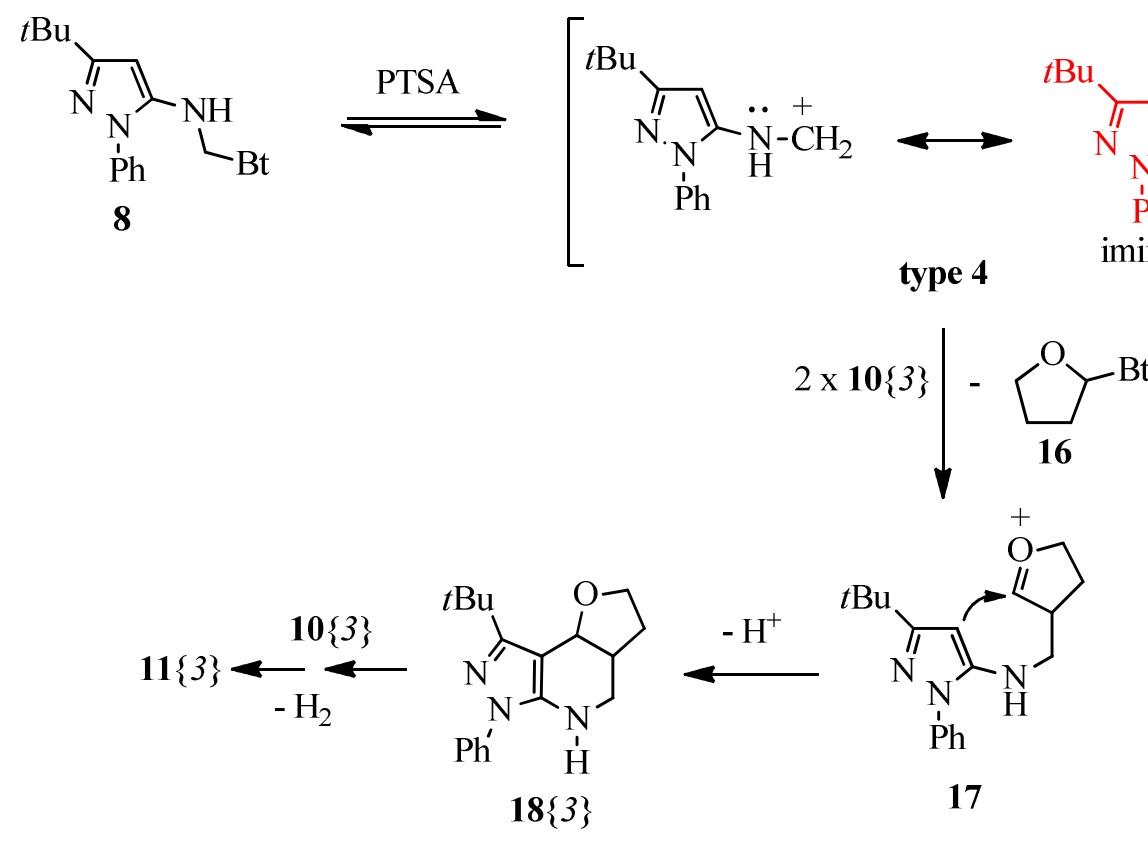

Scheme 5. Proposed stepwise formation of compound $11\{3\}$ and related products. ${ }^{23}$

Finally, compound $\mathbf{1 3}\{2\}$ was obtained from the reaction of either $\mathbf{8}$ or $\mathbf{9}$ starting materials with the unactivated styrene $10\{2\}$ in comparable yields. This finding suggests an isomerization pathway from $\mathbf{8}$ to $\mathbf{9}$ during the course of the reaction, when reaction started with compound $8{ }^{23}$

\section{An Efficient Catalyst-Free Four-Component Synthesis of Novel $\gamma$-Aminoethers Mediated by a Mannich-Type Reaction}

Amino-ethers are valuable building blocks in organic synthesis, in particular, because they are important precursors in the preparation of a wide variety of pharmaceutical products. ${ }^{28-30}$ In the past years, a series of selective serotonine (5-HT)-reuptake inhibitor (SSRI) antidepressants (e.g. Fluoxetine and Paroxetine) and selective norepinephrine (NE)-reuptake inhibitor antidepressants (e.g. Tomoxetine and Viloxazine), have been developed. ${ }^{31}$ Structural examination of such compounds revealed that several of them contain the $\gamma$-amino ether functionality in their structures, Figure 3.

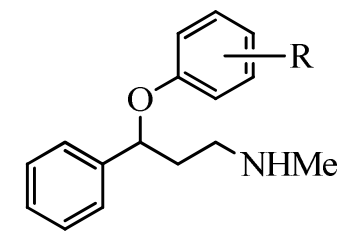

$( \pm)$-Fluoxetine, $\mathrm{R}=4-\mathrm{CF}_{3}$

$( \pm)$-Tomoxetine, $\mathrm{R}=2-\mathrm{CH}_{3}$<smiles>Fc1ccc(C2CCNC[C@H]2COc2ccc3c(c2)OCO3)cc1</smiles>

(-)-Paroxetine<smiles>CCOc1ccccc1OCC1CNCCO1</smiles>

$( \pm)$-Viloxazine

Figure 3. Some $\gamma$-aminoethers of biological interest.

Based on some previous studies, we planned the synthesis of the 2-benzazepine 22 via a one-pot threecomponent Mannich-type reaction. Thus, reaction of $N$-benzylmethylamine $19\{1\}$ (1 equiv), polyformaldehyde 2 (1.2 equiv), $N$-vinyl-2-pyrrolidone 10\{1\} (1 equiv) in methanol (MeOH) 20\{1\} as solvent, at room 
temperature, should afford our expected product 22. Contrary to our expectations, the $\gamma$-aminoether $\mathbf{2 1}\{1,1,1\}$ was isolated instead as unique product. This result indicates that $\mathrm{MeOH}$ acted not only as the solvent but also as nucleophile (reagent), Scheme $6 .^{32}$

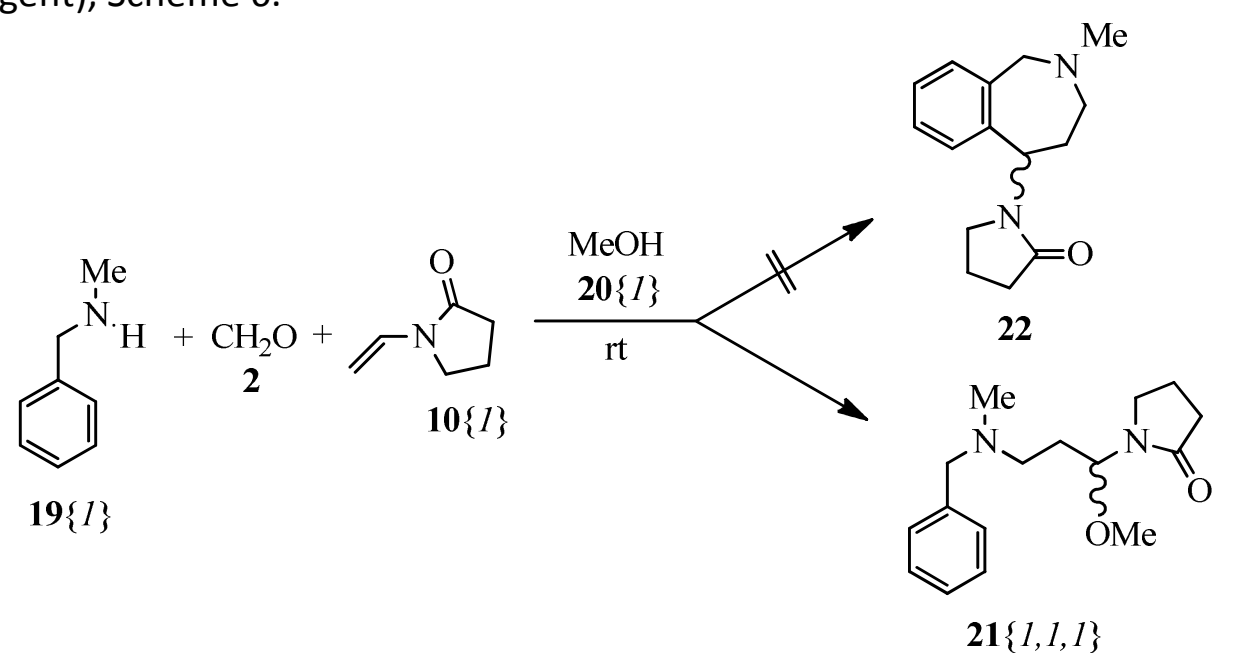

Scheme 6. Synthesis of the novel $\gamma$-aminoether $\mathbf{2 1}\{1,1,1\}$ from the $N$-benzylmethylamine $19\{1\}{ }^{32}$

Based on the literature and our experimental observations, it may be suggested that synthesis of the $\gamma$ aminoether $21\{1,1,1\}$ started with the formation of the well-known iminium ion type 4 from the reaction of the secondary amine $\mathbf{1 9}\{1\}$ with polyformaldehyde 2 . This species is then trapped by the electron-rich alkene $\mathbf{1 0}\{1\}$ via a Mannich-type reaction affording a new cationic species $\mathbf{2 3}$ (stabilized by a resonant effect with the free electronic pair of the $\mathrm{N}$ atom). Finally, the nucleophilic intermolecular attack of the hydroxyl group of the $\mathrm{MeOH}$ over the species 23 led the $\gamma$-aminoether $\mathbf{2 1}\{1,1,1\}$, Scheme 7.

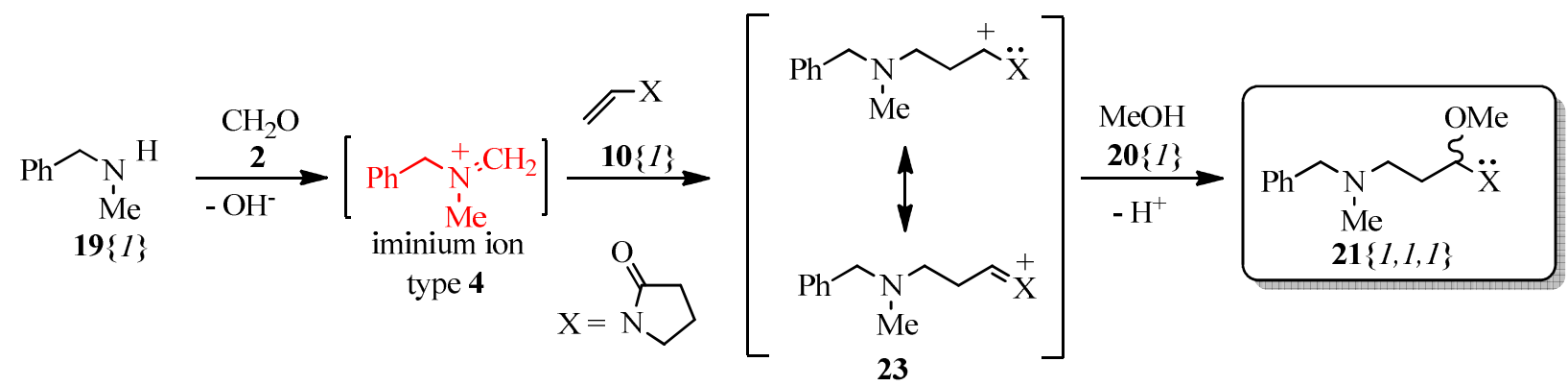

Scheme 7. Proposed mechanistic sequence for the formation of the products $\mathbf{2 1}\{1,1,1\}$ via the iminium ion type $4 .{ }^{32}$

Although, initially we expected an intramolecular cyclization process (ring closure), involving the orthocarbon atom of the Ph-ring in the intermediate species 23 (stabilized by a resonant effect with the free electronic pair of the $X$ substituent), to afford the 2-benzazepinic framework 22, see Scheme 6, such product was not formed. This fact may indicate that the intermolecular nucleophilic attack of the hydroxyl group of the respective $\mathrm{MeOH}$ over the species 23 proceeded faster than the intramolecular ring closure. Steric and conformational factors should be determinant features in this process.

In order to evaluate the scope of these findings and the general character of this multicomponent methodology, a set of secondary amines 19, activated alkenes 10 and diverse alcohols 20 (see figure 4), was subjected to the above established reaction conditions. 
<smiles>CCNCc1ccccc1CNCc1ccccc1</smiles>

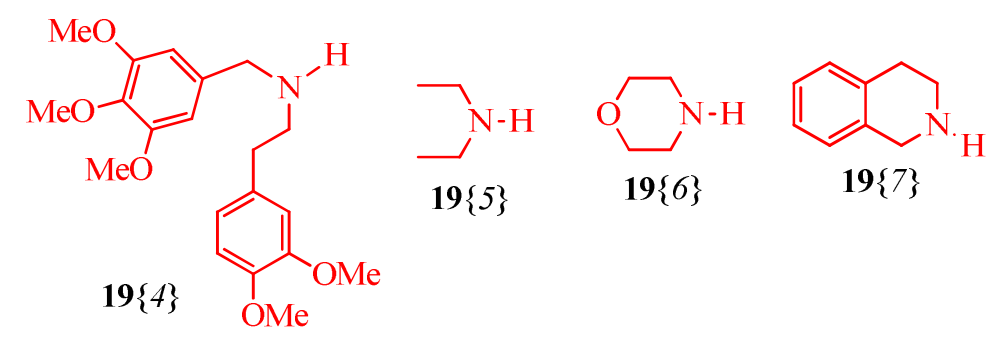<smiles>C=CN1CCCC1=O</smiles>

$\mathrm{H}_{3} \mathrm{C}-\mathrm{OH}$

$20\{1\}$

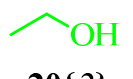

$20\{2\}$<smiles>CCCO</smiles>
$20\{3\}$<smiles>C1=COCCC1</smiles>

$10\{4\}$

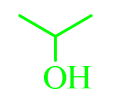

$20\{4\}$

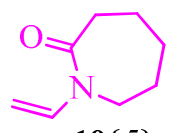

$10\{5\}$

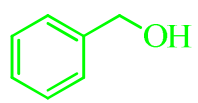

$20\{5\}$

Figure 4. Employed diverse benzylamines 19, terminal alkenes 10 and alcohols 20 reagents for the synthesis of products $21 .^{32}$

As expected, a series of novel $\gamma$-aminoethers $\mathbf{2 1}$ was satisfactorily obtained. The reaction proceeded similarly with yields in the range of $61-91 \%$, as shown in Table 1.

Table 1. Synthesis of the novel $\gamma$-aminoethers $21\{1,1,1\}$ through $21\{7,1,1\}^{32}$

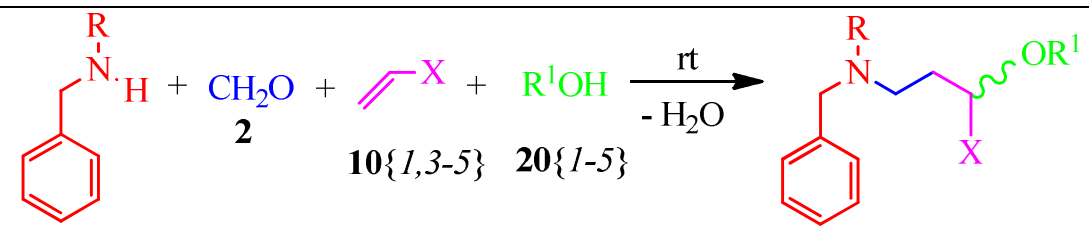

$$
\text { 19 }\{1-4\}
$$

$\mathbf{2 1}\{1,1,1\}-\mathbf{2 1}\{7,1,1\}$<smiles>CO[C@H](CCN(C)Cc1ccccc1)N1CCCC1=O</smiles>

$21\{1,1,1\}, 81 \%$<smiles>CCN(CC[13C](OC)N1CCCC1=O)Cc1ccccc1</smiles>

$21\{2,1,1\}, 73 \%$

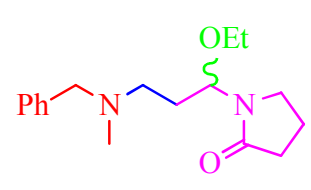

$21\{1,1,2\}, 78 \%$

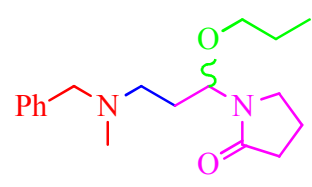

$\mathbf{2 1}\{1,1,3\}, 70 \%$<smiles>CC(C)OB(CCN(C)Cc1ccccc1)N1CCCC1=O</smiles>

$21\{1,1,4\}, 61 \%$<smiles>COC(CCN(C)Cc1ccccc1)N1CCCCCC1=O</smiles>

$21\{1,5,1\}, 86 \%$<smiles>CCN(CC)CCC(OC)N1CCCC1=O</smiles>

$21\{5,1,1\}, 74 \%$<smiles>CCN(Cc1ccccc1)C[C@@H]1CCO[C@@H]1OC</smiles>

cis-21 $\{2,3,1\}, 65 \%$

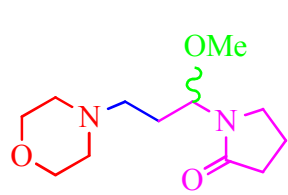

$21\{6,1,1\}, 81 \%$<smiles>CCOC(CCN(Cc1ccccc1)Cc1ccccc1)N1CCCC1=O</smiles>

$21\{3,1,2\}, 68 \%$<smiles>CCCOC(CCN(Cc1ccccc1)Cc1ccccc1)N1CCCC1=O</smiles>

$\mathbf{2 1}\{3,1,3\}, 64 \%$

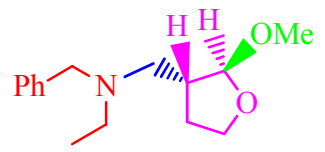

trans-21 $\{2,3,1\}, 26 \%$

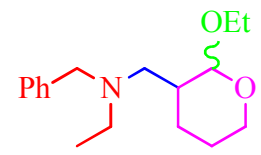

$21\{2,4,2\}, 78 \%$

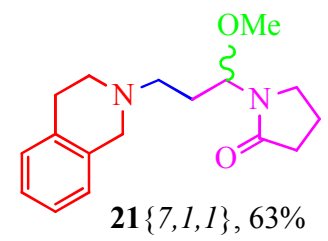


The general character of this approach was confirmed by using not only primary alcohols 20 (MeOH $\{1\}$, $\mathrm{EtOH}\{2\}, \mathrm{PrOH}\{3\}$ and $\mathrm{BnOH}\{5\})$ but also secondary (iPrOH $\{4\}$ ) aliphatic alcohols, although reaction does not proceeded when the tertiary $t \mathrm{BuOH}$ was used. The reaction worked well not only with the enamines ( $N$-vinyl2-pyrrolidinone $10\{1\}$ and $N$-vinylcaprolactam $10\{5\})$ but also with the cyclic vinyl ethers (2,3-dihydrofuran $\mathbf{1 0}\{3\}$ and 3,4-dihydropyran 10\{4\}). No limitation was found for any acyclic or heterocyclic secondary amines used. The reaction proceeded smoothly with sterically less hindered diethylamine $19\{5\}$ but also with the sterically most hindered dibenzylamine $19\{4\}$.

It is also remarkable, that in this one-pot protocol three new bonds were formed in sequence during the process. This finding is in agreement with the atomic economy and bond-forming efficiency (BFE) concepts, which characterizes the multicomponent reactions. ${ }^{9-11}$ Moreover, in the overall process only a molecule of water is removed as by-product, providing also an environmentally friendly character to our four-component procedure. $^{32}$

\section{A Facile Synthesis of Stable $\beta$-Amino- $N-/ O$-Hemiacetals through a Catalyst-Free Three- Component Mannich-Type Reaction}

Hemiacetals are commonly formed when an equivalent of alcohol adds to the carbonyl carbon of an aldehyde. $^{34-37}$ Reaction proceeds in an equilibrium and contrary to the stability displayed by their five- / sixmembered intramolecular cyclic analogues (called lactols), ${ }^{33,34}$ in the most cases, the open chain hemiacetals are intrinsically unstable and the equilibrium tend to favor the parents aldehyde and alcohol. ${ }^{35,36}$ There are $^{3}$ just few examples of stable and isolable open chain hemiacetals, especially from aldehydes bearing electronwithdrawing groups, ${ }^{37-41}$ particularly, several of them derived from chloral. ${ }^{41}$

Trying to overcome the drawback suffered with protic solvents in our failed attempt to obtain the desired 2-benzazepines 22, as described in Scheme 6 (section 3), we decided to repeat the same experiment but using a non-nucleophilic aprotic solvent (i.e. dry acetonitrile, ACN) instead of methanol in order to avoid competition by the cation $\mathbf{2 3}$, Scheme 8 , and address the reaction toward the desired product $\mathbf{2 2}$. After $72 \mathrm{~h}$ of stirring (monitored by TLC), a dense oily material was obtained. Analysis by spectroscopic techniques indicated that the formation of the expected product 22 did not occur again, and instead the unexpected $\beta$-amino- $N$ hemiacetal (also called $\gamma$-aminoalcohol) $\mathbf{2 4}\{1,1\}$ was obtained as the unique product in $71 \%$ isolated yield (Scheme 8 , route 2$)^{42}$

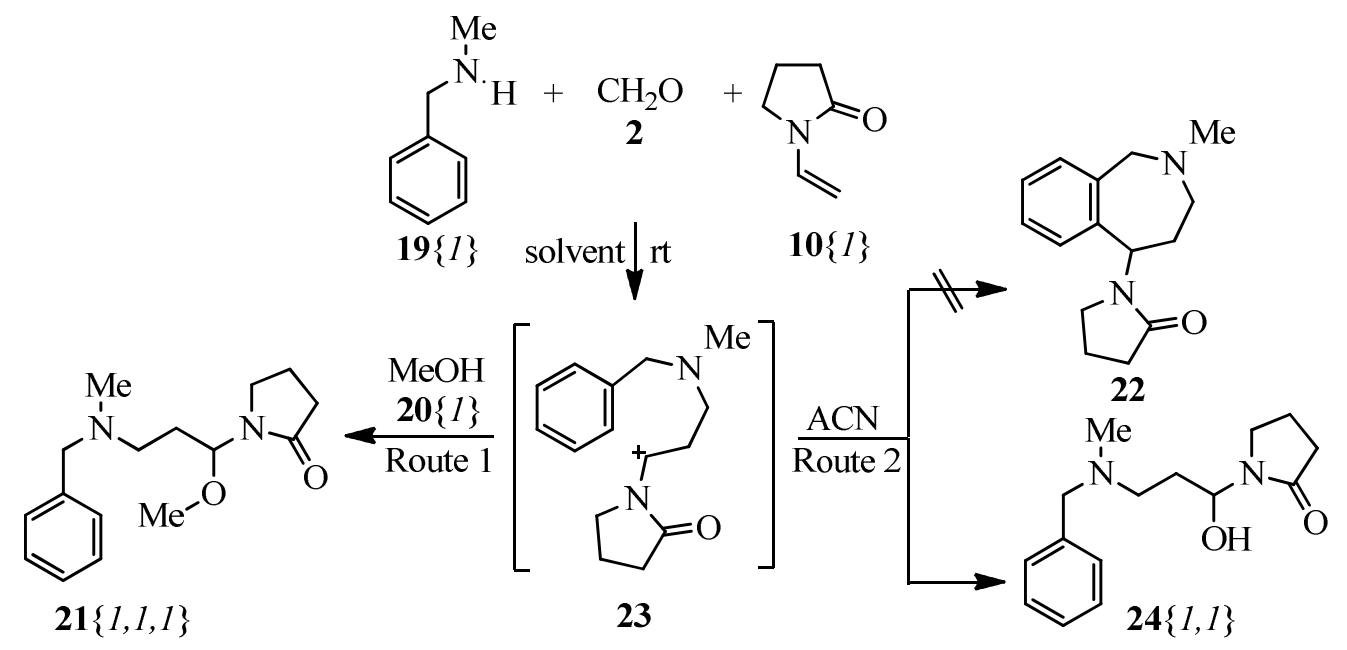

Scheme 8. Synthesis of the novel $\beta$-amino- $N$-hemiacetal $24\{1,1\}$. ${ }^{42}$ 
Although, the aza-hemiacetal $\mathbf{2 4}\{1,1\}$ in principle, was not our expected product, owing to the practical usefulness of its structural parents $\gamma$-aminoalcohols, ${ }^{43-47}$ we decided to explore in more detail, reproducibility and scope of this process. Thus, a chemset of diversely substituted secondary amines 19\{1-21\} and activated alkenes $10\{1,3-4\}$ was evaluated under the established reaction conditions. Satisfactorily, the corresponding $\beta-$ amino- $N$-hemiacetals type $\mathbf{2 4}$ were obtained with yields in the range of 51-93\%, Table 2, except for compound $\mathbf{2 4}\{21,1\}$ (see Table 2 foot note).

Table 2. Three-component synthesis of novel and stable $\beta$-amino- $N$-hemiacetals $2 \mathbf{4}^{42}$

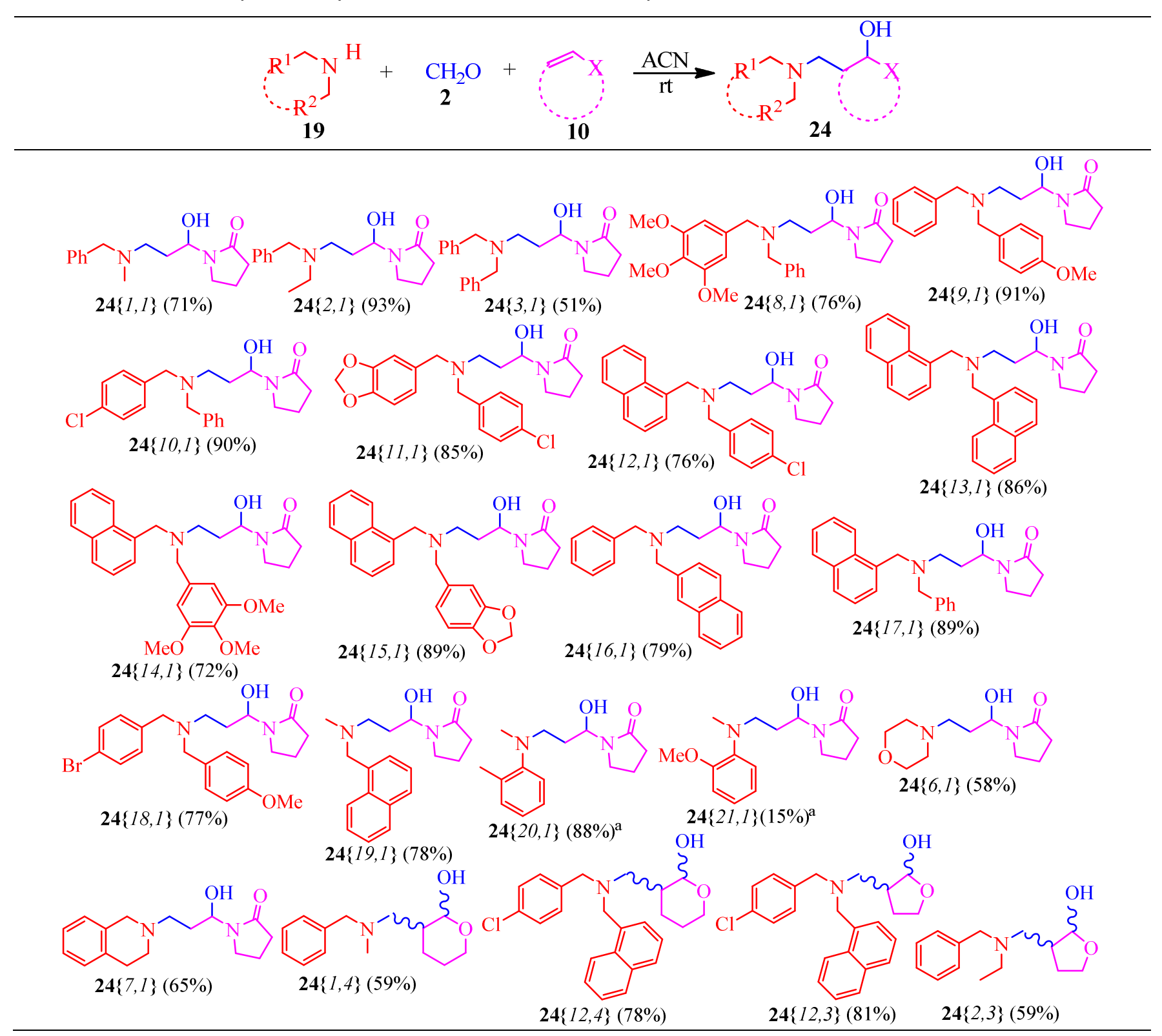

${ }^{a}$ These compounds were obtained as mixtures (95:5) and (17:83) ratios, respectively, along with their cyclization side-products (i.e. 1,2,3,4-tetrahydroquinolines). Reported yields are after isolation from column chromatography.

According to the results, it was suggested that the synthesis of the hemiacetals $\mathbf{2 4}$ commenced with the formation of a hemiaminal $\mathbf{2 5}$ from the reaction of the secondary amine $\mathbf{1 9}$ and formaldehyde $\mathbf{2}$, which should be simultaneously in equilibrium with the aminal 26 and the iminium species type 4 (its counter ion $\mathrm{Y}=\mathrm{OH}^{-}$if 
comes from 25 or $\left(\mathrm{R}^{1} \mathrm{CH}_{2}\right) \mathrm{R}^{2} \mathrm{~N}^{-}$if comes from 26), as shown in Scheme 9. In all cases during the course of the reactions, it was detected by TLC the partial transformation of the secondary amines $\mathbf{1 9}$ into aminals type $\mathbf{2 6}$ although they were completely re-consumed during the reaction. Subsequently, the iminium species type 4 should be trapped by the alkene $\mathbf{1 0}$ via a Mannich-type reaction leading to the carbocationic species type $\mathbf{2 3}$ (stabilized by a resonant effect with the free electronic pair of the X-substituent), through an irreversible process affording the new $\mathrm{C}-\mathrm{C}$ bond. The intermolecular attack of the hydroxyl counter ion or a water molecule over the species type $\mathbf{2 3}$ should led the isolated $\beta$-amino- $N$-/O-hemiacetals $24{ }^{42}$

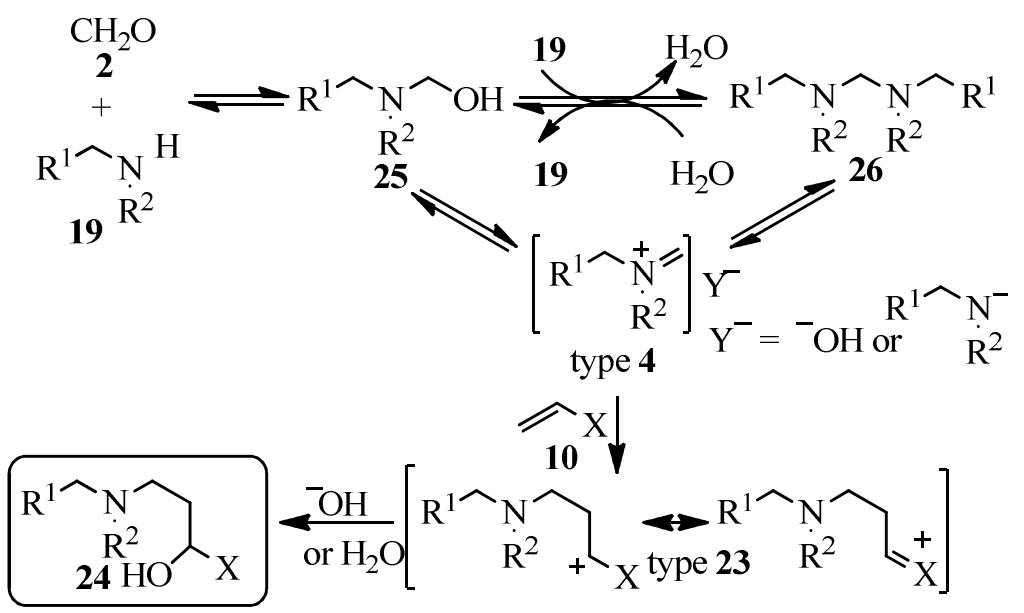

Scheme 9. Proposed mechanistic sequence for the formation of the $\beta$-amino- $N$-/O-hemiacetals 24 via the iminium species type $4 .^{42}$

In order to confirm unequivocally the structure and stability of the obtained $\beta$-amino- $N$ - $/ O$-hemiacetals 24 , the growing of single crystals suitable for X-ray diffraction analysis of compound $\mathbf{2 4}\{16,1\}$ in ethyl ether as solvent at room temperature was performed, see Figure 5.
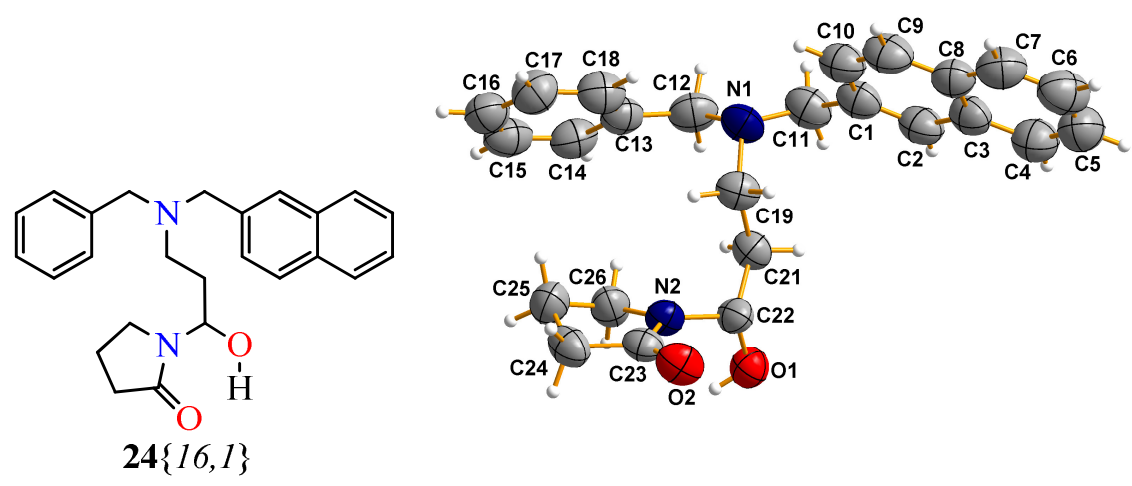

Figure 5. ORTEP drawing of the asymmetric unit for the aza-hemiacetal $\mathbf{2 4}\{16,1\}$; ellipsoids are displayed at the $50 \%$ probability level. $^{42}$

\section{A Straightforward and Efficient Method for the Synthesis of Diversely Substituted $\beta$ - Aminoketones and $\gamma$-Aminoalcohols from 3-( $N, N$-Dimethylamino)propiophenones as Starting Materials through a Mannich-Type Strategy}

Amino-ketones are compounds with superior importance not only for their practical applications displayed by themselves but also because they have been found forming part of the structure of synthetic and naturally 
occurring compounds of diverse practical interest. ${ }^{48,49}$ Thus, Falicain (a local anesthetic and bronchomotor), ${ }^{50}$ compound BE-2254 (antihypertensive and very selective $\alpha_{1}$-adrenoceptor antagonist, precursor of the 3-[ $\left.{ }^{125} \mathrm{I}\right]$ derivative), ${ }^{51}$ Moban (a neuroleptic) ${ }^{52,53}$ and the benzylamine derivative 27 (a potent Jak3 kinase inhibitor), ${ }^{54}$ worth be mentioned as representative examples of this large family of amino-compounds, Figure 6.<smiles>CCCOc1cccc(C(=O)CCN2CCCCC2)c1</smiles><smiles>CN(CCc1ccc(O)cc1)CC1CCc2ccccc2C1=O</smiles><smiles>CCc1c(C)[nH]c2c1C(=O)C(CN1CCOCC1)CC2</smiles>

Moban<smiles>CC(C)N(CCC(=O)c1ccc2ccccc2c1)Cc1ccccc1</smiles>

Figure 6. Some amino-ketones of biological interest.

Due to the importance of the $\gamma$-aminoalcohols described in Table 2 of our previous section 4, we envisioned an alternative and simple (just one- and two-steps) approach for the synthesis of new $\beta$-aminoketones type $\mathbf{3 0}$ (by a Mannich-type strategy), and their subsequent reduction process toward the corresponding novel $\gamma$ tertiary-aminoalcohols type 31, from secondary benzylamines 19 and 3-(N,N-dimethylamino)propiophenone derivatives $\mathbf{2 9}$, as easily accessible starting materials, Scheme $10 .^{55}$

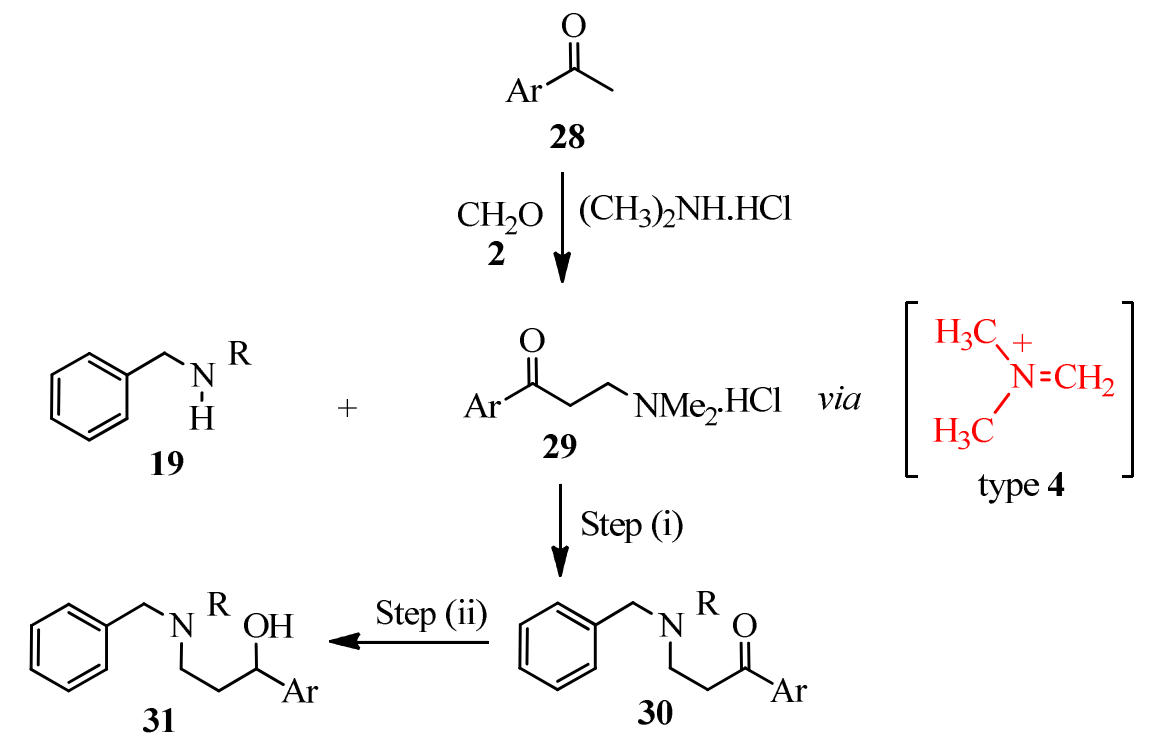

Scheme 10. Proposed sequence for the synthesis of the novel $\beta$-aminoketones $\mathbf{3 0}$ and $\gamma$-aminoalcohols $\mathbf{3 1}$ from the benzylmethylamine derivatives 19 through a Mannich-type strategy. ${ }^{55}$

To start with our purposes, as a model reaction, a mixture of benzylmethylamine $19\{1\}(\mathrm{R}=\mathrm{Me})(1 \mathrm{mmol})$ and $\mathrm{N}, \mathrm{N}$-dimethylaminopropiophenone hydrochloride $29\{1\}(\mathrm{Ar}=\mathrm{Ph})^{56,57}(1 \mathrm{mmol})$ was subjected to different reaction conditions in order to obtain the $\beta$-aminoketone product $30\{1,1\}$ (i.e step (i), Scheme 10). The best result $(88 \%$ yield of product $\mathbf{3 0}\{1,1\})$, was achieved when the starting materials were refluxed in a mixture 5:1 
$v / v$ of $p$-dioxane:TEA. Once established the better reaction conditions and in order to determine its scope and general character, this approach was extended to the benzylamines chemset 19\{1-3,8,22\} and propiophenones chemset $\mathbf{2 9}\{1-4\}$, see Table $3 .^{55}$

Satisfactorily, the corresponding $\beta$-aminoketones 30\{1,1\} through $30\{22,2\}$ were fairly obtained in $62-90 \%$ isolated yields, as shown in the Table 3 . Once the $\beta$-aminoketones $\mathbf{3 0}$ were efficiently obtained, we proceeded with the reduction process of the carbonyl groups, (i.e. step (ii)). The reduction process of ketones $\mathbf{3 0}$ was efficiently performed by two different approaches: (a) by a catalytic hydrogenation on a Parr apparatus in the presence of Nickel-Raney as catalyst, methanol as solvent at room temperature, ${ }^{58,59}$ and (b) by a chemical reduction with $\mathrm{NaBH}_{4}$ in methanol at room temperature to afford the expected $\gamma$-aminoalcohols 31 in (72$93 \%$ ) or (57-96\%) isolated yields, respectively, Table $3 .^{55}$

Table 3. Synthesis of the novel $\beta$-aminoketones $\mathbf{3 0}\{1,1\}$ through $\mathbf{3 0}\{22,2\}$ and $\gamma$-aminoalcohols $\mathbf{3 1}\{1,1\}$ through $31\{22,2\}^{55}$

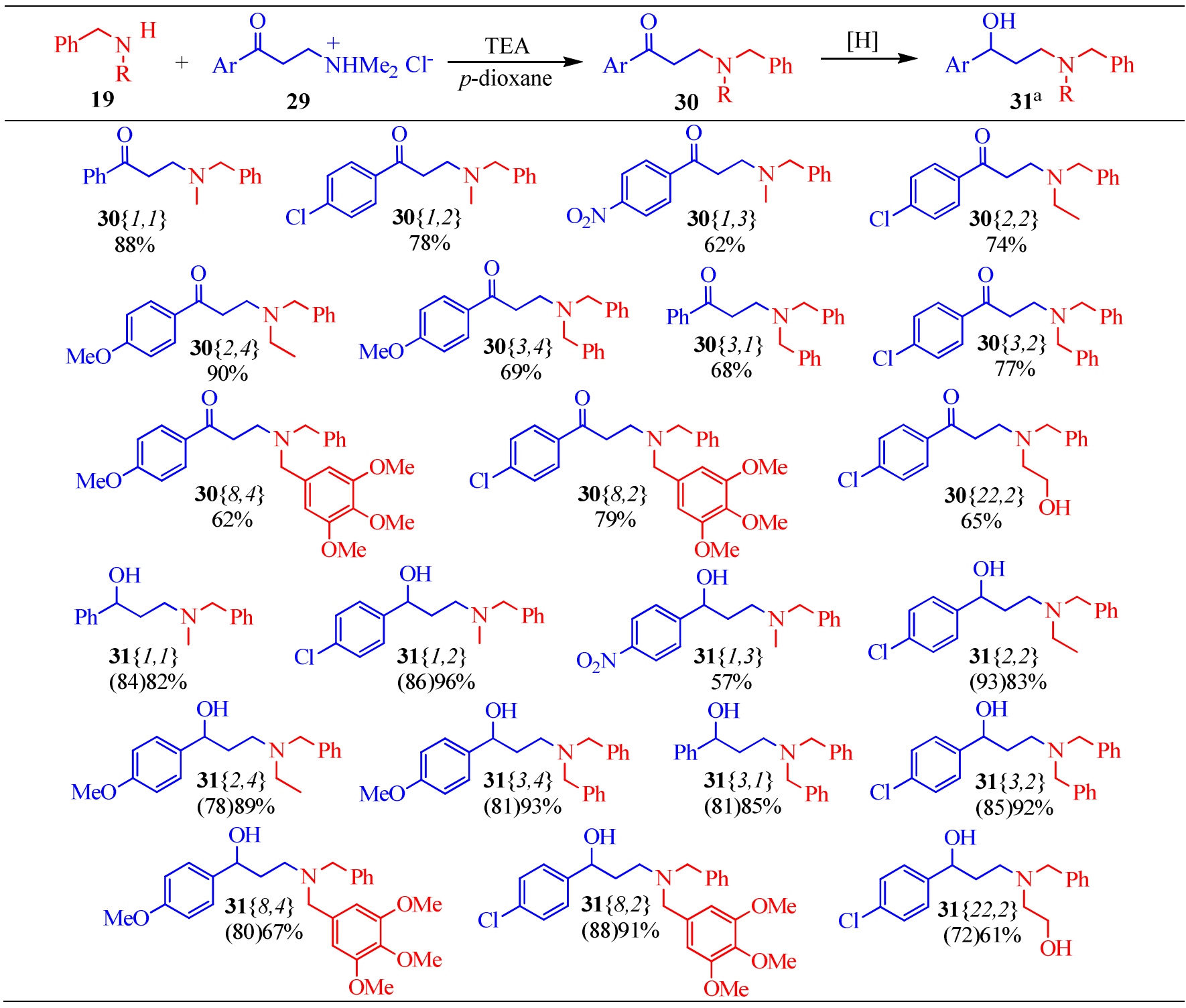

\footnotetext{
${ }^{a}$ Values in parentheses correspond to the isolated yields of alcohols obtained by catalytic hydrogenation.
} 
To evaluate the broadest of this two-step protocol, the heterocyclic derivatives $\mathbf{3 1}\{6,1\}$ and $\mathbf{3 1}\{6,2\}$ were efficiently obtained by treatment of propiophenones $29\{1\}$ and $29\{2\}$, respectively, with morpholine $\mathbf{1 9}\{6\}$ and the subsequent reduction of their carbonyl groups. Likewise, the $\beta$-aminoketone $30\{23,4\}$ was fairly obtained from the reaction of propiophenone $29\{4\}$ with piperidine $19\{23\}$. Interestingly, the piperidine derivative $30\{23,4\}$ is structurally close to the anesthetic Falicain, see Figure 6 . This approach could become into an alternative synthetic route for Falicain and derivatives, Scheme $11 .{ }^{55}$

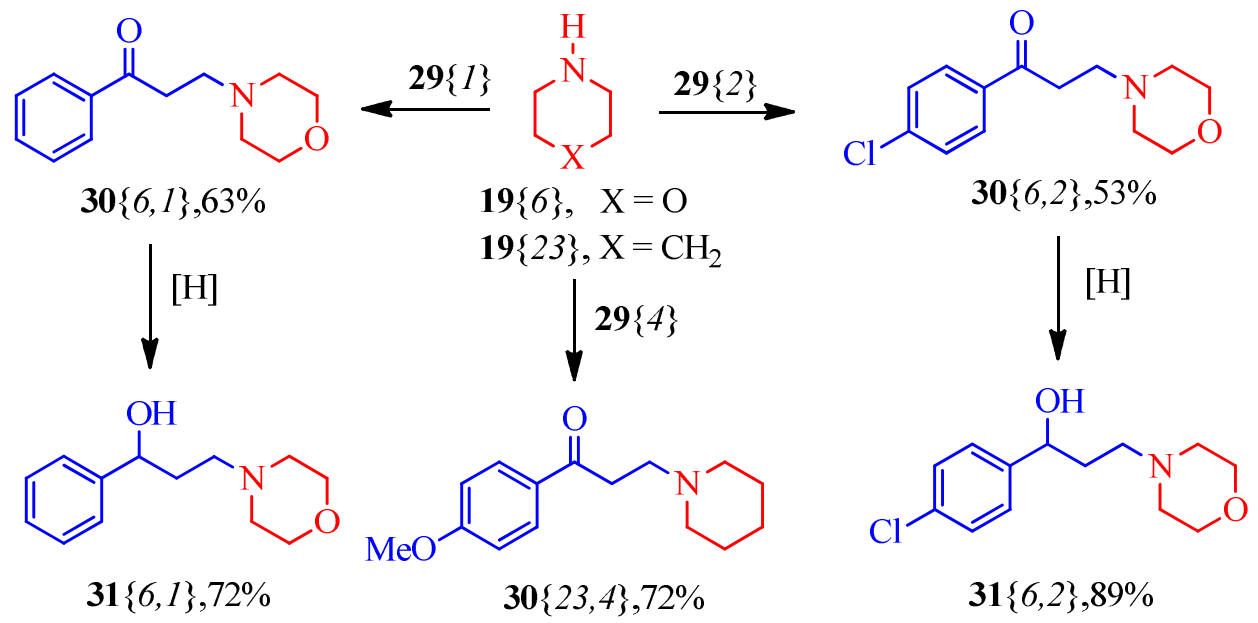

Scheme 11. Synthesis of novel $\beta$-aminoketones $(\mathbf{3 0}\{6,1\}, \mathbf{3 0}\{6,2\}$ and $\mathbf{3 0}\{23,4\})$ and $\gamma$-aminoalcohols $(\mathbf{3 1}\{6,1\}$ and $31\{6,2\})$ from the reaction of propiophenones $(29\{1\}, 29\{2\}$ and $29\{4\}$ with morpholine $19\{6\}$ and piperidine $19\{23\}$, respectively. ${ }^{55}$

To further confirm the practical scope of our two-step protocol, we used it to develop an alternative synthetic route towards Naftifine ${ }^{\circledR}$, a recognized and highly active antifungal agent. ${ }^{60-62}$ Thus, following the synthetic sequence described in Scheme 12 Naftifine ${ }^{\oplus}$ was satisfactorily obtained in $86 \%$ isolated yield. ${ }^{55}$

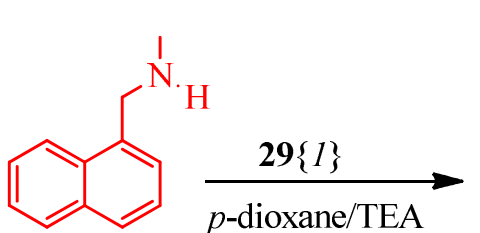

$19\{19\}$<smiles>CN(CCC(=O)c1ccccc1)Cc1cccc2ccccc12</smiles>

$\mathbf{3 0}\{19,1\}$
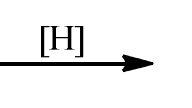

1 $31\{19,1\}$

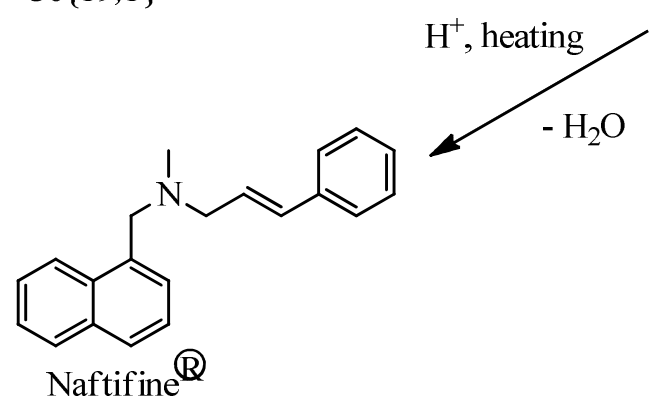

Scheme 12. Alternative synthetic route for the antifungal agent Naftifine ${ }^{\oplus 5}$ 


\section{A Straightforward Synthesis of 4,7-Disubstituted 1,4-Oxazepanes via a Brønsted Acid- Catalyzed Intramolecular Etherification Reaction}

The 1,4-oxazepane ring is a seven-membered heterocycle containing nitrogen and oxygen in 1,4-positions, which is endowed with a wide range of biological activities, ${ }^{63-65}$ and it is found in diverse natural products such as the neurotoxin ( \pm )-batrachotoxinin A 32, ${ }^{66}$ as well as, synthetic derivatives like derivatives $\mathbf{3 3}$ and 34 acting as peripheral-selective noradrenaline reuptake inhibitors ${ }^{67}$ and the sordarin analog 35 which showed a potent antifungal activity against Candida albicans, ${ }^{68}$ (Figure 7).

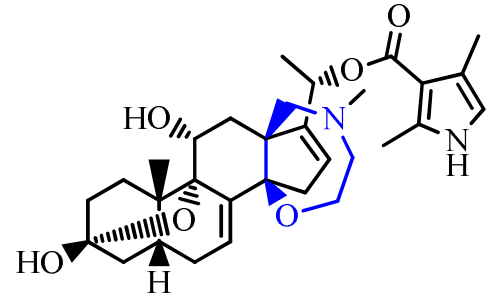

32

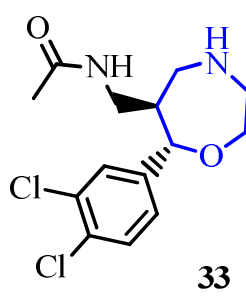

33
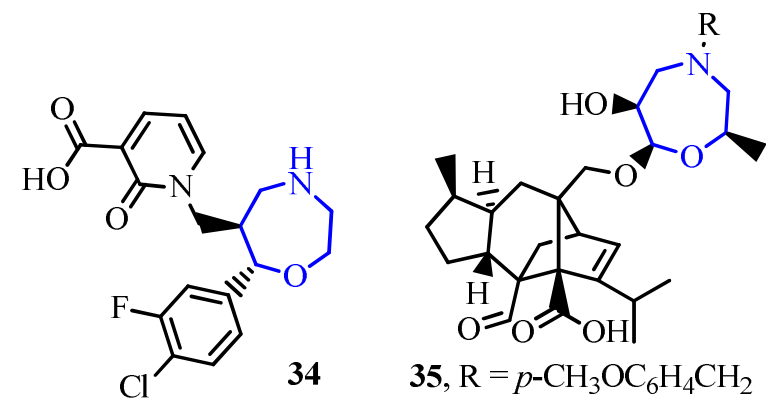

35, $\mathrm{R}=p-\mathrm{CH}_{3} \mathrm{OC}_{6} \mathrm{H}_{4} \mathrm{CH}_{2}$

Figure 7. Some representative examples of biologically active 1,4-oxazepanes.

Although many synthetic methods for this $\mathrm{N}, \mathrm{O}$-heterocycle have been documented, most of them are focused on fused benzoxazepine derivatives. ${ }^{69,70}$ In fact, an exhaustive searching of the literature revealed that very few synthetic approaches for non-fused 1,4-oxazepanes have been reported. ${ }^{71-73}$ Because of the potential synthetic utility of the $\gamma$-aminoalcohols described in Tables 2 and 3 of our previous sections 4 and 5, we envisioned two alternative and straightforward routes for the synthesis of diversely substituted 1,4oxazepanes $\mathbf{3 6}$ via an intramolecular etherification reaction of $N$-tethered bis-alcohols type $\mathbf{2 4}$ and $\mathbf{3 1}$ as the key intermediates for these processes. ${ }^{74}$

Initially, we planned a three-component Mannich-type reaction/intramolecular etherification sequence under catalyst-free conditions in order to construct the 1,4-oxazepane framework type 36, (Scheme 13). To test the feasibility of this strategy, a mixture of $N$-benzylethanolamine 19\{22\} (1.0 equiv), polyformaldehyde 2 (1.5 equiv), $N$-vinyl-2-pyrrolidone $10\{1\}$ (1.1 equiv) and acetonitrile $(2.0 \mathrm{~mL}$ ) was stirred at room temperature for $48 \mathrm{~h}$. After purification of the obtained residue three main components were isolated corresponding to the expected 1,4-oxazepane $36\{22,1\}$ in 52\% yield along with the 3-benzyloxazolidine $37\{22\}$ (28\% yield) and the $N$-tethered bis-alcohol $\mathbf{2 4}\{22,1\}$ in $13 \%$ yield (Scheme 13). Subjecting diethanolamine $\mathbf{1 9}\{24\}$ to the above established reaction conditions afforded the 1,4-oxazepane derivative $36\{24,1\}$ in $46 \%$ yield as the main component. Nevertheless, attempts to improve the yielding of the 1,4-oxazepanes 36 or reducing the number of side-products by modifying the reaction conditions were unfruitful. ${ }^{74}$ 


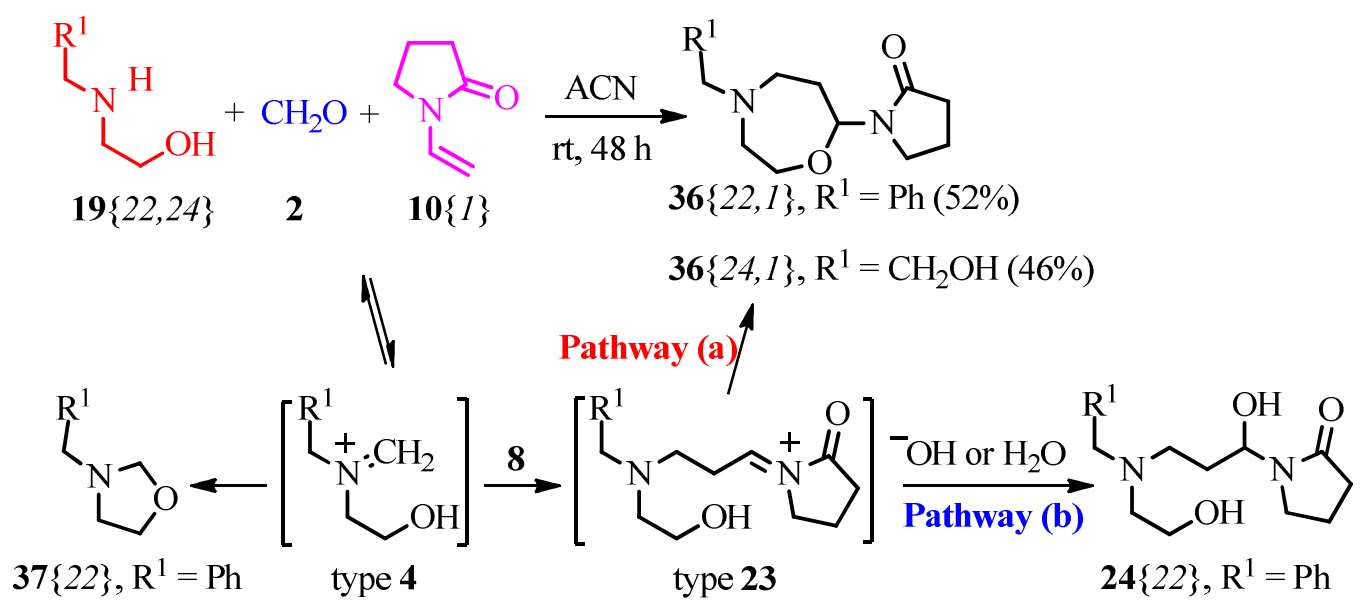

Scheme 13. Synthesis of novel 1,4-oxazepanes 36 through a three-component Mannich-type reaction. ${ }^{74}$

Then, we visualized a second alternative strategy for the synthesis of the 1,4-oxazepanes type 36 but this time, through the intramolecular etherification of previously formed $N$-tethered bis-alcohols type $\mathbf{3 1}$ (Scheme $14)^{74}$

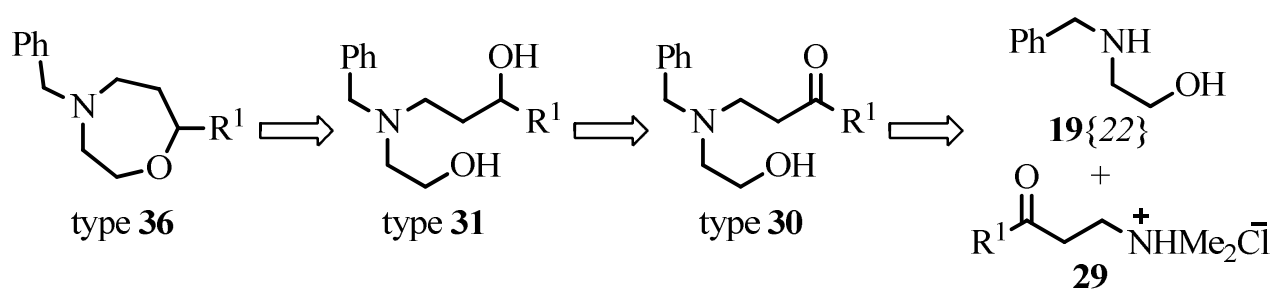

Scheme 14. Retrosynthetic approach for the synthesis of the 1,4-oxazepanes type 36 from $\mathrm{N}$-tethered bisalcohols type $31 .^{74}$

After several assays the best reaction conditions to convert bis-alcohols type $\mathbf{3 1}$ into 1,4-oxazepanes type 36 corresponded to the couple $\mathrm{H}_{2} \mathrm{SO}_{4} / p$-dioxane, Table 4.

Table 4. Synthesis of novel 4,7-disubstitued 1,4-oxazepanes 36 through a $\mathrm{H}_{2} \mathrm{SO}_{4}$ catalyzed intramolecular etherification reaction ${ }^{74}$

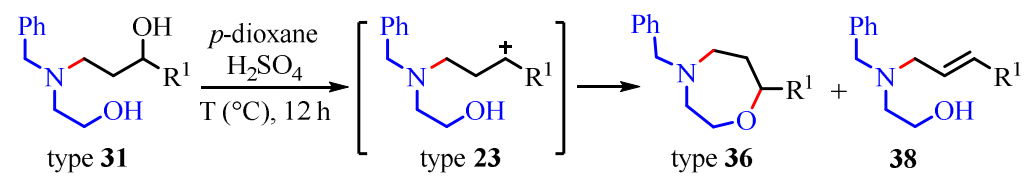

\begin{tabular}{ccccc}
\hline Entry & $\mathrm{R}^{1}$ & $\mathrm{~T}\left({ }^{\circ} \mathrm{C}\right)$ & $\begin{array}{c}\text { Yield 36 } \\
(\%)\end{array}$ & $\begin{array}{c}\text { Yield 38 } \\
(\%)\end{array}$ \\
\hline 1 & $4-\mathrm{MeOC}_{6} \mathrm{H}_{4}$ & 30 & $\{22,4\}(89)$ & $\{22,4\}(6)$ \\
2 & $3,4-$ & 40 & $\{22,5\}(81)$ & -- \\
& $\left(\mathrm{OCH}_{2} \mathrm{O}\right) \mathrm{C}_{6} \mathrm{H}_{3}$ & & & -- \\
3 & $3,4,5-$ & 40 & $\{22,6\}(88)$ & \\
& $(\mathrm{MeO})_{3} \mathrm{C}_{6} \mathrm{H}_{2}$ & & & \\
\hline
\end{tabular}


Table 4. Continued

\begin{tabular}{|c|c|c|c|c|}
\hline Entry & $\mathrm{R}^{1}$ & $\mathrm{~T}\left({ }^{\circ} \mathrm{C}\right)$ & $\begin{array}{c}\text { Yield } 36 \\
(\%)\end{array}$ & $\begin{array}{c}\text { Yield } 38 \\
(\%)\end{array}$ \\
\hline 4 & 4- $\mathrm{MeC}_{6} \mathrm{H}_{4}$ & 60 & $\{22,7\}(85)$ & -- \\
\hline 5 & Dh & 60 & $\{22,1\}(82)$ & $\{22,1\}(7)$ \\
\hline 6 & 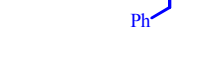 & 60 & $\{22,8\}(68)$ & -- \\
\hline 7 & $4-\mathrm{BrC}_{6} \mathrm{H}_{4}$ & 80 & $\{22,9\}(51)$ & -- \\
\hline 8 & $4-\mathrm{ClC}_{6} \mathrm{H}_{4}$ & 80 & $\{22,2\}(46)$ & $\{22,2\}(19)$ \\
\hline 9 & $2-\mathrm{ClC}_{6} \mathrm{H}_{4}$ & 80 & $\begin{array}{c}\{22,10\} \\
(42)\end{array}$ & $\begin{array}{c}\{22,10\} \\
(20)\end{array}$ \\
\hline 10 & & 30 & $\begin{array}{c}\{22,11\} \\
(90)\end{array}$ & -- \\
\hline 11 & $4-\mathrm{O}_{2} \mathrm{NC}_{6} \mathrm{H}_{4}$ & $70-90$ & $\{22,3\}(--)$ & $\{22,3\}(--)$ \\
\hline
\end{tabular}

According to experimental details and the results depicted in Table 4, the temperature plays an important role in the regioselectivity of this reaction, as well as, the nature of the (hetero)aromatic ring (i.e. $R^{1}$ ) attached to the secondary carbon atom holding the hydroxyl group in $\mathbf{3 1}$, to afford selectively either 1,4-oxazepanes 36 or the side-product allylamines $38 .^{74}$

\section{Summary}

Through this review, libraries of diverse nitrogen-containing structures have been reported whose synthesis started from the simple molecule of formaldehyde (pure or masked) as common precursor, in all cases, involving the Mannich-type reaction in any step of their processes. These results correspond to a humble contribution of the author and his collaborators to the Diversity Oriented Synthesis (DOS), considered by many as an emerging, fascinating and powerful tool, currently disposable for the Organic Synthesis as well as for the Medicinal Chemistry.

\section{Acknowledgements}

RA wishes to credit to all members of the Research Group of Heterocyclic Compounds (GICH) for their valuable collaboration in the different synthetic approaches. He also wants to acknowledge professors Justo Cobo, Manuel Nogueras, Herbert Meier and Alan R. Katritzky (in his memory) for their valuable support to this research work during the last years. Additionally, COLCIENCIAS, Banco de la República and Universidad del Valle are also acknowledged for financial support.

\section{References}

1. Dömling, A. Org. Chem. Highlights 2005, April 5. 
2. Cordoba, A.; Watanabe, S.; Tanaka, F.; Notz, W.; Barbas, C. F. J. Am. Chem. Soc. 2002, 124, $1866-1867$. http://dx.doi.10.1021/ja017833p

3. Jarusiewicz, J.; Choe, Y.; Yoo, K. S.; Park, C. P.; Jung, K. W. J. Org. Chem. 2009, 74, 2873-2876. http://dx.doi.10.1021/jo900163w

4. Kumar, A.; Maurya, R. A. Synlett. 2008, 883-885. http://dx.doi.10.1055/s-2008-1042908

5. Akritopoulou-Zanze, I.; Gracias, V.; Djuric, S. W. Tetrahedron Lett. 2004, 45, 8439-8441. http://dx.doi.org/10.1016/j.tetlet.2004.09.117

6. Ryabukhin, S. V.; Plaskon, A. S.; Ostapchuk, E. N.; Volochnyuk, D. M.; Tolmachev, A. A. Synthesis 2007, 417-427.

http://dx.doi.10.1055/s-2007-965881

7. Andrade, C. K. Z.; Takada, S. C. S.; Suarez, P. A. Z.; Alves, M. B. Synlett 2006, 1539-1541. http://dx.doi.10.1055/s-2006-941606

8. Okamoto, K.; Yamamoto, T.; Kanbara, T. Synlett 2007, 2687-2690.

http://dx.doi.10.1055/s-2007-991073

9. Tietze, L. F. Chem. Rev. 1996, 96, 115-136. http://dx.doi.10.1021/cr950027e

10. Dömling, A. in Multicomponent reactions (Eds.: Zhu, J.; Bienaymé, H), Wiley-VCH, Weinheim, 2005, pp 76-80.

11. Coquerel, Y.; Boddaert, T.; Presset, M.; Mailhol, D.; Rodriguez, J. in Ideas in chemistry and molecular sciences: Advances in synthetic chemistry (Ed.: Pignataro, B.), Wiley-VCH, Weinheim, 2010, pp 187-202.

12. Arend, M.; Westermann, B.; Risch, N. Angew. Chem. Int. Ed. 1998, 37, 1044-1070. http://dx.doi.10.1002/(SICI)1521-3773(19980504)37:8<1044::AID-ANIE1044>3.0.CO;2-E

13. Tramontini, M.; Angiolini, L. in Mannich-bases, chemistry and uses. CRC, Boca Raton, FL, 1994.

14. Burke, M. D.; Schreiber, S. L. Angew. Chem. Int. Ed. 2004, 43, 46-58. http://dx.doi.10.1002/anie.200300626

15. Maclean, D.; Baldwin, J. J.; Ivanov, V. T.; Kato, Y.; Shaw, A.; Schenider, P.; Gordon, E. M. J. Comb. Chem. 2000, 2, 562-578.

http://dx.doi.10.1021/cc000071u

16. Lee, D.; Sello, J. K.; Schreiber, S. L. Org. Lett. 2000, 2, 709-712.

http://dx.doi.10.1021/ol005574n

http://dx.doi.org/10.1016/i.tet.2004.07.028

17. de Mello, H.; Echevarria, A.; Bernardino, A.; Canto-Cavalheiro, M.; Leon, L. L. J. Med. Chem. 2004, 47, 5427-5432.

http://dx.doi.10.1021/jm0401006

18. Warshakoon, N. C.; Wu, S.; Boyer, A.; Kawamoto, R.; Renock, S.; Xu, K.; Pokross, M.; Evdokimov, A. G.; Zhou, S.; Winter, C.; Walter, R.; Mekel, M. Bioorg. Med. Chem. Lett. 2006, 16, 5687-5690.

http://dx.doi.org/10.1016/j.bmcl.2006.08.017

19. Hamblin, J. N.; Angell, T. D. R.; Ballantine, S. P.; Cook, C. M.; Cooper, A. W. J.; Dawson, J.; Delves, C. J.; Jones, P. S.; Lindvall, M.; Lucas, F. S.; Mitchell, C. J. Bioorg. Med. Chem. Lett. 2008, 18, 4237-4241. http://dx.doi.org/10.1016/i.bmcl.2008.05.052

20. Katritzky, A. R.; Abonia, R.; Yang, B.; Qi, M.; Insuasty, B. Synthesis 1998, 1487-1490. http://dx.doi.10.1055/s-1998-2165 
21. Abonia, R.; Albornoz, A.; Insuasty, B.; Quiroga, J.; Meier, H.; Hormaza, A.; Nogueras, M.; Sánchez, A.; Cobo, J.; Low, J. N. Tetrahedron 2001, 57, 4933-4938.

http://dx.doi.org/10.1016/S0040-4020(01)00436-7

22. Abonia, R.; Rengifo, E.; Quiroga, J.; Insuasty, B.; Sánchez, A.; Cobo, J.; Low, J. N.; Nogueras, M. Tetrahedron Lett. 2002, 43, 5617-5620.

https://doi.org/10.1016/S0040-4039(02)01115-2

23. Abonia, R.; Rengifo, E.; Quiroga, J.; Insuasty, B.; Cobo, J.; Nogueras, M. Tetrahedron 2004, 60, 88398843.

http://dx.doi.org/10.1016/S0040-4039(02)01115-2

24. Compound $\mathbf{8}$ is formed from $\mathbf{7}$ in methanolic solution as termodinamic product. Its lower reactivity toward heterocyclization reaction was also confirmed, please see ref. 23.

25. Low, J. N.; Cobo, J.; Nogueras, M.; Sánchez, A.; Rengifo, E.; Abonia, R. Acta Cryst. 2002, E58, $053-054$. http://dx.doi.10.1107/S1600536801020670

26. Katritzky, A. R.; Lan, X.; Lam, J. N. J. Org. Chem. 1991, 56, 4397-4403.

http://dx.doi.10.1021/jo00014a014

27. Katritzky, A. R.; Rogovoy, B. V. Chem. Eur. J. 2003, 9, 4586-4593.

http://dx.doi.10.1002/chem.200304990

28. Cavalluzzi, M. M.; Catalano, A; Bruno, C.; Lovece, A.; Carocci, A.; Corbo, F.; Franchini, C.; Lentini, G.; Tortorella, V. Tetrahedron: Asymm. 2007, 18, 2409-2417.

http://dx.doi.org/10.1016/i.tetasy.2007.10.002

29. Franchini, C.; Carocci, A.; Catalano, A.; Cavalluzzi, M. M.; Corbo, F.; Lentini, G.; Scilimati, A.; Tortorella, P.; Camerino, D. C.; De Luca, A. J. Med. Chem. 2003, 46, 5238-5248.

http://dx.doi.10.1021/im030865y

30. Huang, K.; Ortiz-Marciales, M.; Correa, W.; Pomales, E.; López, X. Y. J. Org. Chem. 2009, 74, 4195-4202. http://dx.doi.10.1021/jo900666r

31. Pinder, R. M.; Wieringa, J. H. Med. Res. Rev. 1993, 13, 259-325.

http://dx.doi.10.1002/med.2610130304

32. Abonia, R.; Castillo, J.; Insuasty, B.; Quiroga, J.; Nogueras, M.; Cobo, J. ACS Comb. Sci. 2013, 15, 2-9. http://dx.doi.10.1021/co300105t

33. Moss, G. P.; Smith, P. A. S.; Tavernier, D. Pure Appl. Chem. 1995, 67, 1307-1375.

http://dx.doi.org/10.1351/pac199567081307

34. Liu, J.; Wong, C-H. Angew. Chem. Int. Ed. 2002, 41, 1404-1407.

http://dx.doi.10.1002/1521-3773(20020415)41:8<1404::AID-ANIE1404>3.0.CO;2-G

35. See:

www.chtf.stuba.sk/ szolcsanyi/education/files/Chemia\%20heterocyklickych\%20zlucenin/Prednaska\%20 6/Odporucane\%20studijne\%20materialy/Acetaly.pdf.

36. Chiang, Y.; Kresge, J. J. Org. Chem. 1985, 50, 5038-5040.

http://dx.doi.10.1021/jo00225a007

37. Meester, W. J. N.; van Maarseveen, J. H.; Schoemaker, H. E.; Hiemstra, H.; Rutjes, F. P. J. T. Eur. J. Org. Chem. 2003, 2519-2529.

http://dx.doi.10.1002/ejoc.200200714

38. Gunaratne, H. Q. N.; Nockemann, P.; Seddon, K. R. Chem. Commun. 2015, 51, 4455-4457. http://dx.doi.10.1039/C5CC00099H

39. Vinogradov, V. M.; Starosotnikov, A. M.; Shevelev, S. A. Mendeleev Commun. 2002, 12, $198-200$. 
http://dx.doi.org/10.1070/MC2002v012n05ABEH001641

40. See: Cloxotestosterone at: www.chemicalbook.com/ProductChemicalPropertiesCB61178371_EN.htm.

41. Ram, R. N.; Meher, N. K. Tetrahedron 2002, 58, 2997-3001. http://dx.doi.org/10.1016/S0040-4020(02)00185-0

42. Abonia, R.; Castillo, J.C.; Garay, A.; Insuasty, B.; Quiroga, J.; Nogueras, M.; Cobo, J.; D'Vries, R. Tetrahedron Lett. 2017, 58, 1490-1494.

http://dx.doi.org/10.1016/j.tetlet.2017.02.084

43. Lait, S. M.; Rankic, D. A.; Keay, B. A. Chem. Rev. 2007, 107, 767-796.

http://dx.doi.10.1021/cr050065q

44. Szakonyi, Z.; Gonda, T.; Ötvös, S. B.; Fülöp, F. Tetrahedron: Asymm. 2014, 25, 1138-1145. http://dx.doi.10.1016/j.tetasy.2014.06.017

45. Kotland, A.; Accadbled, F.; Robeyns, K.; Behr, J. B. J. Org. Chem. 2011, 76, 4094-4098. http://dx.doi.10.1021/jo200176u

46. Yardley, J. P.; Husbands, G. E. M.; Stack, G.; Butch, J.; Bicksler, J.; Moyer, J. A.; Muth, E. A.; Andree, T.; Fletcher, H.; James, M. N. G.; Sielecki, A. R. J. Med. Chem. 1990, 33, 2899-2905. http://dx.doi.10.1021/jm00172a035

47. Gais, H. J.; Greibel, C.; Buschmann, H. Tetrahedron: Asymm. 2000, 11, 917-928. http://dx.doi.org/10.1016/S0957-4166(00)00008-2

48. Tanaka, N.; Tamai, T.; Mukaiyama, H.; Hirabayashi, A.; Muranaka, H.; Ishikawa, T.; Akahane, S.; Akahane, M. Bioorg. Med. Chem. 2001, 9, 3265-3271.

http://dx.doi.org/10.1016/S0968-0896(01)00240-1

49. Korošec, T.; Ačimovič, J.; Seliškar, M.; Kocjan, D.; Fon-Tacer, K.; Rozman, D.; Urleb, U. Bioorg. Med. Chem. 2008, 16, 209-221.

http://dx.doi.org/10.1016/i.bmc.2007.10.001

50. Marcus, R.; Gloye, E.; Florance, E. Comput. Chem. 1977, 1, 235-241.

http://dx.doi.org/10.1016/0097-8485(77)85015-8

51. Pupo, A.; Uberti, M.; Minneman, K. Eur. J. Pharmacol. 2003, 462, 1-8.

http://dx.doi.org/10.1016/S0014-2999(03)01292-5

52. Alper, K.; Barry, J.; Balabanov, A. Epilepsy Behav. 2002, 3, 13-18. http://dx.doi.org/10.1016/S1525-5069(02)00500-5

53. Szeszko, P.; Bilder, R.; Dunlop, J.; Walder, D.; Lieberman, J. Biol. Psychiatry 1999, 45, 680-686. http://dx.doi.org/10.1016/S0006-3223(98)00258-3

54. Brown, B.; Bamford, A.; Bowyer, J.; James, D.; Rankine, N.; Tang, E.; Torr, V.; Culbert, E. Bioorg. Med. Chem. Lett. 2000, 10, 575-579.

http://dx.doi.org/10.1016/S0960-894X(00)00051-2

55. Abonia, R.; Arteaga, D.; Castillo, J.; Insuasty, B.; Quiroga, J.; Ortíz, A. J. Braz. Chem. Soc. 2013, 24, 13961402.

http://dx.doi.org/10.5935/0103-5053.20130177

56. Compounds $\mathbf{2 8}$ were obtained following the classical Mannich reaction between the corresponding acetophenone, dimethylamine hydrochloride and polyformaldehyde in refluxing ethanol.

57. Jeffery, G. H.; Bassett, J.; Mendham, J.; Denney, R. C. Vogel's Textbook of Practical Organic Chemistry, 4th ed.; Longman Inc.: New York, USA, 1978, p. 815.

58. Rylander, P. N. in Hydrogenation Methods; Academic: New York, 1985.

59. Tarasevich, V. A.; Kozlov, N. G. Russ. Chem. Rev. 1999, 68, 55-72. 
60. Petranyi, G.; Georgopoulos, A.; Mieth, H. Antimicrob. Agents Chemother. 1981, 19, 390-392. http://dx.doi.10.1128/AAC.19.3.390

61. Gupta, A. K; Ryder, J. E.; Cooper, E. A. J. Cutan. Med. Surg. 2008, 12, 51-58. http://dx.doi.org/10.2310/7750.2008.06009

62. Petranyi, G.; Ryder, N. S.; Stütz, A. Science 1984, 224, 1239-1241.

63. Kaneko, S.; Arai, M.; Uchida, T.; Harasaki, T.; Fukuoka, T.; Konosu, T. Bioorg. Med. Chem. Lett. 2002, 12, 1705-1708. http://dx.doi.org/10.1016/S0960-894X(02)00290-1

64. Audouze, K.; Nielsen, E.; Peters, D. J. Med. Chem. 2004, 47, 3089-3104. http://dx.doi.10.1021/jm031111m

65. Sharma, G.; Park, J. Y.; Park, M. S. Bioorg. Med. Chem. Lett. 2008, 18, 3188-3191. http://dx.doi.org/10.1016/j.bmcl.2008.04.067

66. Kurosu, M.; Marcin, L. R.; Grinsteiner, T. J.; Kishi, Y. J. Am. Chem. Soc. 1998, 120, 6627-6628. http://dx.doi.10.1021/ja981258g

67. Yukawa, T.; Nakada, Y.; Sakauchi, N.; Kamei, T.; Yamada, M.; Ohba, Y.; Fujimori, I.; Ueno, H. Takiguchi, M.; Kuno, M.; Kamo, I.; Nakagawa, H.; Fujioka, Y.; Igari, T.; Ishichi, Y.; Tsukamoto, T. Bioorg. Med. Chem. 2016, 24, 3716-3726. http://dx.doi.org/10.1016/i.bmc.2016.06.014

68. Serrano-Wu, M. H.; Laurent, D. R.; Chen, Y.; Huang, S.; Lam, K.-R.; Matson, J. A.; Mazzucco, C. E.; Stickle, T. M.; Tully, T. P.; Wong, H. S.; Vyas, D. M.; Balasubramanian, B. N. Bioorg. Med. Chem. Lett. 2002, 12, 2757-2760. http://dx.doi.org/10.1016/S0960-894X(02)00529-2

69. Hu, F.; Liu, H.; Jia, J.; Ma, C. Org. Biomol. Chem. 2016, 14, 11076-11079. http://dx.doi.10.1039/C6OB02098D

70. Zhu, C.-Q.; Deng, Z.-F.; Zhang, Y.; Wang, Y.-Q. Org. Chem. Front. 2017, 4, 196-203. http://dx.doi.10.1039/C6Q000545D

71. Deka, M. J.; Indukuri, K.; Sultana, S.; Borah, M.; Saikia, A. K. J. Org. Chem. 2015, 80, 4349-4359. http://dx.doi.10.1021/acs.joc.5b00049

72. Gharpure, S. J.; Prasad, J. V. K. Eur. J. Org. Chem. 2013, 2076-2079. http://dx.doi.10.1002/ejoc.201300135

73. Vo, C.-V.; Luescher, M. U.; Bode J. W. Nat. Chem. 2014, 6, 310-314. http://dx.doi.10.1038/NCHEM.1878

74. Castillo, J.-C.; Portilla, J.; Insuasty, B.; Quiroga, J.; Abonia, R. Curr. Org. Synth. 2017, DOI: $10.2174 / 1570179414666171011160917$. 


\section{Authors' Biographies}

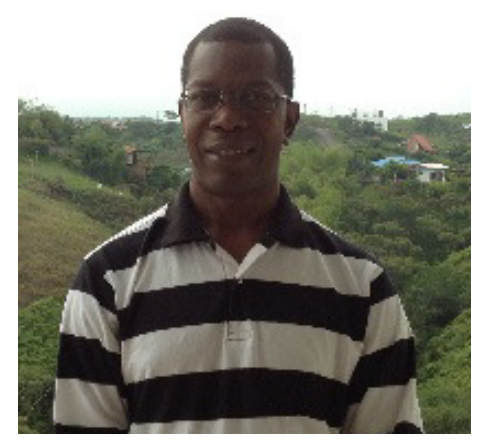

Dr. Rodrigo Abonia was born in Jamundí, Colombia, 1966. He obtained his B.Sc. degree in Chemistry from the Universidad del Valle, Cali, Colombia, in 1990 and qualified for his Ph.D. degree at the same university in 1997, on the synthesis of benzodiazepines and other nitrogen-containing small-ring heterocycles of potential biological activity under the supervision of Dr Braulio Insuasty. He was Scholar Research in the Florida Center for Heterocyclic Compounds at University of Florida in 1996 under the supervision of Prof. Dr. Alan R. Katritzky, studying the use of the benzotriazole methodology in the synthesis of novel heterocyclic compounds. He is Full Professor of Organic Chemistry in the Department of Chemistry at Universidad del Valle since 1997 and currently, he is a member of the Research Group of Heterocyclic Compounds (GICH) at the same university. He has authored/co-authored over 180 scientific publications including two reviews. His main research interests are the organic synthesis, heterocyclic chemistry, asymmetric synthesis, natural products, synthetic methodologies and biological applications of nitrogen-containing heterocycles, multicomponent reactions, among others.

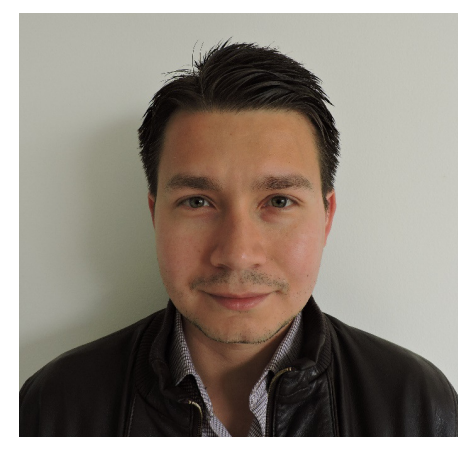

Dr. Juan-Carlos Castillo was born in Cali (Colombia) in 1983. He received his B.Sc. in Chemistry from the Universidad del Valle (Colombia) in 2008 and his Ph.D. from the same university under the supervision of Prof. Rodrigo Abonia in 2013. He then moved to Aix-Marseille Université (France) to join the Institut des Sciences Moléculaires de Marseille as a postdoctoral associate under the supervision of Prof. Jean Rodriguez and Prof. Yoann Coquerel. Then, he moved back to Colombia and worked as a postdoctoral associate at Universidad de los Andes in the group of Prof. Jaime Portilla in 2015. He is currently assistant professor at Universidad de Boyacá (Colombia). His research focuses on the development of multiple bond-forming reactions via iminium ion and aryne intermediates and their applications in medicinal chemistry. 